\title{
Summertime increases in upper-ocean stratification and mixed-layer depth
}

https://doi.org/10.1038/s41586-021-03303-x

Received: 8 December 2019

Accepted: 26 January 2021

Published online: 24 March 2021

Check for updates

\author{
Jean-Baptiste Sallée ${ }^{1 凶}$, Violaine Pellichero ${ }^{2,3}$, Camille Akhoudas' $^{1}$, Etienne Pauthenet ${ }^{1}$, \\ Lucie Vignes', Sunke Schmidtko ${ }^{4}$, Alberto Naveira Garabato ${ }^{5}$, Peter Sutherland ${ }^{6}$ \& \\ Mikael Kuusela ${ }^{7}$
}

The surface mixed layer of the world ocean regulates global climate by controlling heat and carbon exchange between the atmosphere and the oceanic interior ${ }^{1-3}$. The mixed layer also shapes marine ecosystems by hosting most of the ocean's primary production ${ }^{4}$ and providing the conduit for oxygenation of deep oceanic layers. Despite these important climatic and life-supporting roles, possible changes in the mixed layer during an era of global climate change remain uncertain. Here we use oceanographic observations to show that from 1970 to 2018 the density contrast across the base of the mixed layer increased and that the mixed layer itself became deeper. Using a physically based definition of upper-ocean stability that follows different dynamical regimes across the global ocean, we find that the summertime density contrast increased by $8.9 \pm 2.7$ per cent per decade $\left(10^{-6}-10^{-5}\right.$ per second squared per decade, depending on region), more than six times greater than previous estimates. Whereas prior work has suggested that a thinner mixed layer should accompany a more stratified upper ocean ${ }^{5-7}$, we find instead that the summertime mixed layer deepened by $2.9 \pm 0.5$ per cent per decade, or several metres per decade (typically 5-10 metres per decade, depending on region). A detailed mechanistic interpretation is challenging, but the concurrent stratification and deepening of the mixed layer are related to an increase in stability associated with surface warming and high-latitude surface freshening ${ }^{8,9}$, accompanied by a wind-driven intensification of upper-ocean turbulence ${ }^{10,11}$. Our findings are based on a complex dataset with incomplete coverage of a vast area. Although our results are robust within a wide range of sensitivity analyses, important uncertainties remain, such as those related to sparse coverage in the early years of the 1970-2018 period. Nonetheless, our work calls for reconsideration of the drivers of ongoing shifts in marine primary production, and reveals stark changes in the world's upper ocean over the past five decades.
The fundamental vertical structure of the world ocean consists of three main layers: the surface mixed layer, which continually exchanges heat, freshwater, carbon and other climatically important gases with the atmosphere; the pycnocline, characterized by its pronounced stratification-that is, an enhanced density contrast between shallower and deeper layers, which inhibits cross-layer vertical mixing; and the deep ocean, which is largely isolated from the atmosphere (Fig. 1; some regions have an additional layer between the mixed layer and the pycnocline, which is termed 'barrier layer' and is associated with an enhanced vertical salinity gradient ${ }^{12}$ ). Changes in the surface and pycnocline layers can have widespread consequences for climate, as they may alter the rates at which exchanges occur between the surface and the deep ocean. For example, increased pycnocline stratification will expectedly weaken surface-to-depth exchanges as enhanced density gradients decouple surface and subsurface waters, act to shoal the surface mixed layer, and result in reduced air-sea gas transfer, deep-ocean ventilation and biological productivity ${ }^{3,13-15}$. Detecting and understanding physical changes in the ocean's surface and pycnocline layers is thus essential to determine the role of the ocean in climate, and predict climate change and its ecosystem impacts. The latest Special Report on Ocean and Cryosphere in a Changing Climate from the Intergovernmental Panel on Climate Change (IPCC) ${ }^{16}$ clearly identifies this aspect of oceanic evolution as highly policy-relevant. Changes in the surface mixed-layer depth and pycnocline stratification feature prominently in the report's summary for policymakers, and in multiple contexts including ocean de-oxygenation, nutrient

${ }^{1}$ Sorbonne Université, CNRS/IRD/MNHN, LOCEAN, IPSL, Paris, France. ${ }^{2}$ Institute for Marine and Antarctic Studies, University of Tasmania, Hobart, Tasmania, Australia. ${ }^{3} \mathrm{CSIRO}$ Oceans and Atmosphere, Hobart, Tasmania, Australia. ${ }^{4}$ GEOMAR Helmholtz Centre for Ocean Research Kiel, Kiel, Germany. ${ }^{5}$ Ocean and Earth Science, National Oceanography Centre, University of

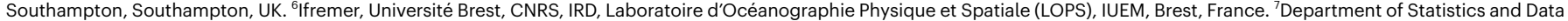
Science, Carnegie Mellon University, Pittsburgh, PA, USA. ${ }^{\bowtie e}$-mail: jean-baptiste.sallee@locean-ipsl.upmc.fr 


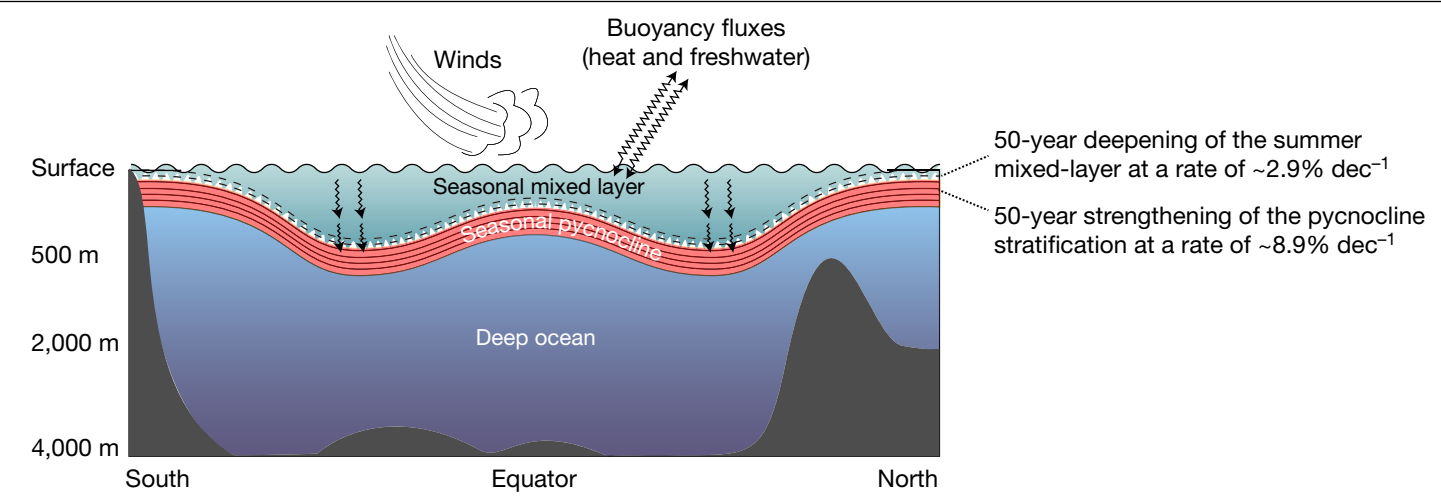

Fig. 1 The three-layer structure of the world ocean. Schematic of an idealized meridional section across the world ocean illustrating the ocean's three-layer structure. The upper seasonal mixed layer is stirred by a range of turbulent processes driven by wind and buoyancy forcings (see Methods section 'Dynamical forcing of changes in mixed-layer depth'). The seasonal pycnocline emerges from the density contrast (that is, stratification) between surface and deep waters, and acts as a barrier that reduces communication between surface and deep waters. The deep ocean is largely insulated from the atmosphere, but climate signals propagate from and to the deep ocean through mixing across the seasonal pycnocline and/or through direct contact with the mixed layer as seasonal pycnocline stratification is eroded in winter. Here, we present 50-year trends in both mixed-layer depth and pycnocline stratification, with impacts on upper-ocean structure and deep-ocean ventilation. supply to living organisms in the mixed layer, and the global energy budget.

Despite its far-reaching climatic effects, the variability in the mixed-layer depth and pycnocline strength have not been examined in a systematic fashion from observations. A few studies have documented changes in upper-ocean stratification, but they have done so by focusing on mixed-layer depth variations at specific locations ${ }^{17}$ or on changes in stratification averaged over a fixed depth range (generally $0-200 \mathrm{~m}$, $0-1,000 \mathrm{~m}$ or $0-2,000 \mathrm{~m}$ ) that conflates the distinct dynamical regimes of the mixed layer, pycnocline and deep ocean ${ }^{1,8,9,18,19}$. For instance, stratification over $0-200 \mathrm{~m}$, which has been widely used in past studies, entirely misses pycnocline changes in regions where the mixed layer is deeper than $200 \mathrm{~m}$ (typically at high latitudes in the Southern Ocean and North Atlantic) and can underestimate pycnocline changes where the mixed layer is shallower than $200 \mathrm{~m}$ (such as in the tropics and the subtropical ocean), especially when the mixed-layer depth also evolves in time (see Methods, Extended Data Fig. 1). As a result, we currently lack a physically consistent assessment of the climatic evolution of upper-ocean structure, and we do not know whether or how this structure is being affected by global climate change. It is generally expected that, in a warming world, the mixed layer will shoal and the pycnocline stratification will increase $\mathrm{e}^{1,20}$, because the ocean surface warms more rapidly than deeper layers, and oceanic freshening by enhanced ice melting and precipitation at high latitudes is surface-intensified ${ }^{1}$. This expectation, however, is yet to be tested on a global scale.

Here, we address this challenge by performing an assessment of the multi-decadal evolution of the mixed layer and pycnocline across the world ocean. Stratification over a fixed 0-200 m layer is also computed for comparison with previous studies ${ }^{1,8,9,18,19}$. We combine different sources of in situ temperature and salinity observations obtained between 1970 and 2018 (see Methods, Extended Data Fig. 2). Notably, our analysis includes observations from instrumented marine mammals, which afford robust and consistent coverage of the climatically important subpolar Southern Ocean ${ }^{21,22}$. For each of these observations, we calculate the mixed-layer depth and pycnocline strength (that is, the squared buoyancy frequency, $N^{2}$, expressed in $\mathrm{s}^{-2}$ ) directly below the mixed layer (see Methods), as well as the $0-200 \mathrm{~m}$ stratification, $N_{200}^{2}$, which provide us with more than three million estimates of each quantity distributed between $80^{\circ} \mathrm{S}$ and $80^{\circ} \mathrm{N}(60 \%$ in the Northern Hemisphere, $40 \%$ in the Southern Hemisphere). We then fit a linear-regression model based on generalized least squares, locally around each grid point (see Methods), to produce a global, finely resolved seasonal climatology and the associated linear temporal trend estimates. Data selection is based on a rigorously tested data-mapping procedure ${ }^{21,23-25}$, temporal and spatial decorrelation scales used in the regression model are estimated from the data ${ }^{26}$, and uncertainties associated with each individual observation are propagated through the model to produce standard error maps for the climatology and the associated trends (see Methods for details). Because of the large seasonal cycle that characterizes the upper ocean, all our results are presented by season, where 'summer' ('winter') refers to August-October in the Northern (Southern) Hemisphere and to January-March in the Southern (Northern) Hemisphere. The fields referred to hereafter as 'climatological fields' are seasonal means estimated for year 2000 , computed from the monthly weighted local linear regression (see Methods). In regions where salinity-driven barrier layers are present between the mixed layer and the pycnocline (mostly in the tropics ${ }^{12}$ ), the variable referred to as 'pycnocline strength'-that is, the density gradient at the base of the density-defined mixed layer (see Methods)-is actually a measure of the salinity-driven density contrast between the mixed layer and the barrier layer. Thus, in such regions, our methodology tends to underestimate density contrasts and changes associated with the pycnocline.

On basin and seasonal time scales, the climatological mixed-layer depth generally mirrors the pycnocline stratification, with shallower mixed layers in regions of stronger pycnocline stratification, and vice versa (Fig. 2). Both the spatial pattern and seasonal evolution of the pycnocline and 0-200 m stratification are consistent, although pycnocline stratification exhibits more structure, arguably because it is associated with a dynamically consistent layer of the ocean across all regions and seasons. Pycnocline stratification is stronger in summer than in winter, as the mixed-layer deepening induced by the wintertime intensification of upper-ocean turbulence (driven by the de-stratifying forcings of oceanic buoyancy loss, wind and wave ${ }^{27}$ ) erodes the increased summer stratification. Pycnocline stratification then increases from winter to summer, and the mixed layer shoals, in response to stratifying forcings (for example, solar warming and high-latitude sea-ice melt) and relaxation of de-stratifying forcings. In summer, the deepest mixed layers are found in the Southern Ocean, co-located with the year-round intense westerly winds in this region (Fig. 2e). This summertime geographical pattern suggests that regional differences are at least partially driven by a balance between stratifying buoyancy fluxes and de-stratifying wind-driven turbulence. In winter, the deepest mixed layers occur in the subpolar North Atlantic and directly to the north of the Antarctic Circumpolar Current in the Indian and Pacific basins $\mathrm{s}^{21,28-30}$ (Fig. 2f). 


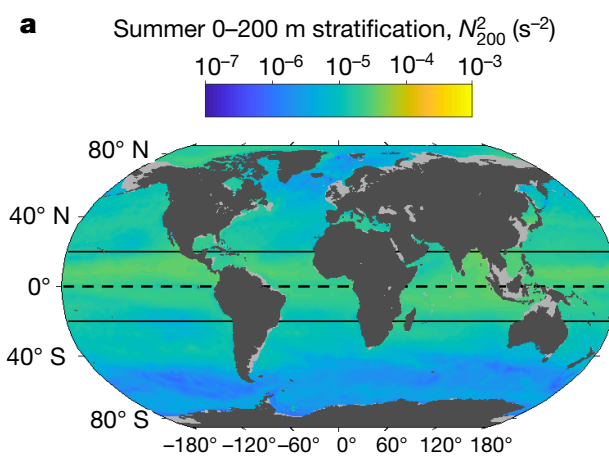

C Summer pycnocline stratification, $N^{2}\left(\mathrm{~s}^{-2}\right)$ $\begin{array}{lllll}10^{-7} & 10^{-6} & 10^{-5} & 10^{-4} & 10^{-3}\end{array}$

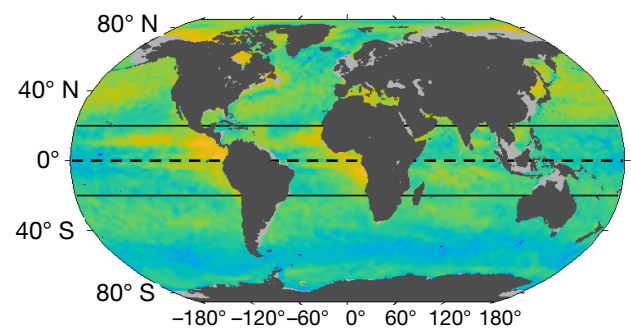

e $\quad \begin{array}{ccc}\text { Summer mixed-layer depth }(\mathrm{m}) \\ 0 & 50 & 100\end{array}$

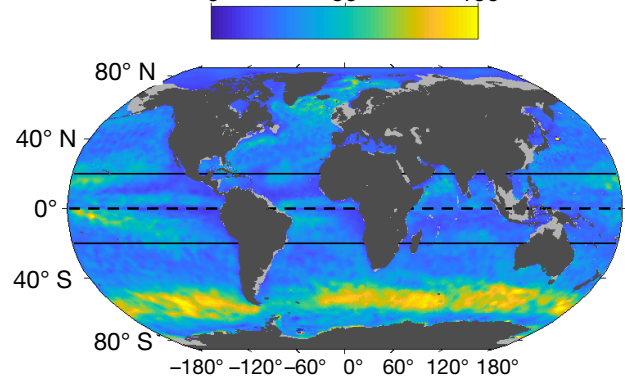

b

Winter 0-200 m stratification, $N_{200}^{2}\left(\mathrm{~s}^{-2}\right)$

$\begin{array}{lllll}10^{-7} & 10^{-6} & 10^{-5} & 10^{-4} & 10^{-3}\end{array}$

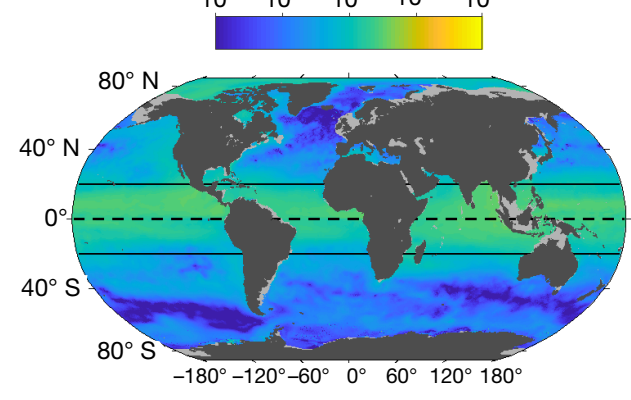

d Winter pycnocline stratification, $N^{2}\left(\mathrm{~s}^{-2}\right)$

$$
\begin{array}{lllll}
10^{-7} & 10^{-6} & 10^{-5} & 10^{-4} & 10^{-3}
\end{array}
$$

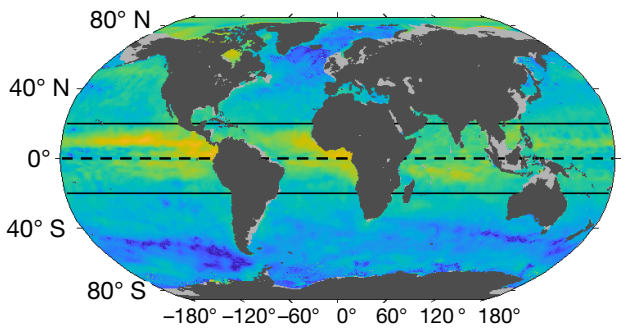

f
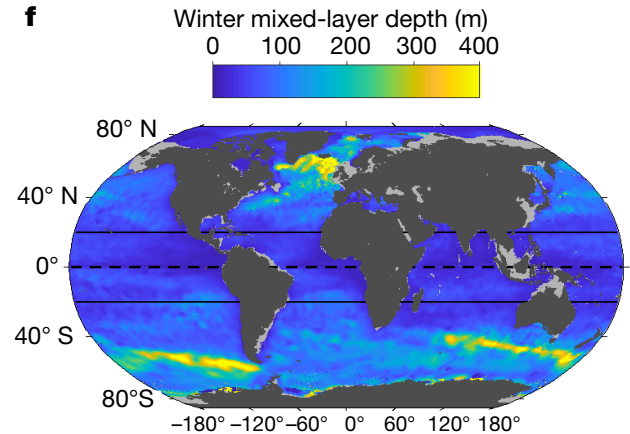

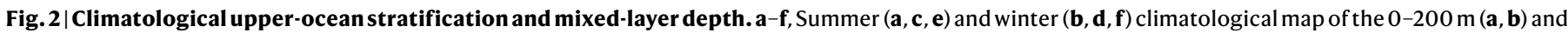
pycnocline (c, d) stratification and mixed-layer depth $(\mathbf{e}, \mathbf{f})$ over the world ocean.

\section{Seasonal pycnocline changes}

Summertime pycnocline stratification has increased worldwide across all ocean basins since 1970, at a rate ranging from $10^{-6} \mathrm{~s}^{-2} \mathrm{dec}^{-1}$ to $10^{-5} \mathrm{~s}^{-2} \mathrm{dec}^{-1}$ (Fig. 3b). Trends display a marked regional pattern, with greater trends in the tropics (about $10^{-5} \mathrm{~s}^{-2}$ ) than at high latitudes (about $10^{-6} \mathrm{~s}^{-2}$ ). Consistent with pycnocline stratification, the $0-200 \mathrm{~m}$ stratification also shows a global increase, although at a lower rate, ranging from $10^{-7} \mathrm{~s}^{-2} \mathrm{dec}^{-1}$ to $10^{-6} \mathrm{~s}^{-2} \mathrm{dec}^{-1}$ (Fig. 3a). Overall, regions with stronger climatological stratification have experienced larger changes than regions with weaker climatological stratification. As a result, the per cent change from local climatological stratification is broadly consistent across all latitudes, and the global-mean per cent change is $8.9 \pm 2.7 \% \mathrm{dec}^{-1}$ (mean \pm one standard error; Table 1$)$. This global-mean per cent change of pycnocline stratification is considerably higher than the equivalent rate of change of the 0-200 m stratification estimated here with the same methodology, which is only $1.3 \pm 0.3 \% \mathrm{dec}^{-1}$ (Table 1). Using a dynamically consistent framework to analyse the ocean's vertical structure thus reveals upper-ocean density contrasts increasing at a rate 6 -7 times higher than when considering a fixed (that is, non-dynamical) 0-200 $\mathrm{m}$ reference frame. The latter glaringly misrepresents the increase in upper-ocean stratification that has occurred globally over the past five decades. Notably, our estimate of 0-200 m stratification change is consistent with previous annual-mean estimates of the same variable from the IPCC Fifth Assessment Report ${ }^{31}\left(1 \% \mathrm{dec}^{-1}\right)$, from the latest IPCC Special Report ${ }^{16}\left(0.46-0.51 \% \mathrm{dec}^{-1}\right)$, and from more recent works using individual observational databases ${ }^{9}\left(0.6-1.1 \% \mathrm{dec}^{-1}\right)$ and a range of gridded observational products ${ }^{8}\left(1.2 \pm 0.1 \% \mathrm{dec}^{-1}\right.$ using the IAP product, $1.2 \pm 0.4 \% \mathrm{dec}^{-1}$ using the Ishii product, $0.7 \pm 0.5 \% \mathrm{dec}^{-1}$ using the EN4 product, $0.9 \pm 0.5 \% \mathrm{dec}^{-1}$ using the ORAS4 product and $1.2 \pm 0.3 \% \mathrm{dec}^{-1}$ using the NCEI product; see Li et al. ${ }^{8}$ for details on each of these products and associated references). Our diagnostics of pycnocline stratification change complement preceding views that relied on a fixed 0-200 m layer (which gives a false impression of more moderate upper-ocean change than in reality), and call for a careful revisiting of the impacts of the upper ocean's evolution in assessments of future climate change and corresponding adaptation strategies. Although our quantification of the wintertime pycnocline stratification change is more uncertain, owing to the comparatively modest number of winter observations, it does reveal a very clear strengthening of pycnocline stratification too (see Methods, Extended Data Figs. 5, 6).

The pycnocline stratification can be linearly decomposed into contributions associated with vertical gradients in temperature and in salinity (see Methods). Over much of the world ocean, the density contrast of the pycnocline is mainly linked to the vertical temperature gradient (warmer waters overlying cooler waters; Fig. 4a); however, we note that in the tropics and at high latitudes, salinity is either dominant over or has a comparable effect to the temperature. The strong 


$$
\text { a Summer 0-200 m stratification trend }
$$

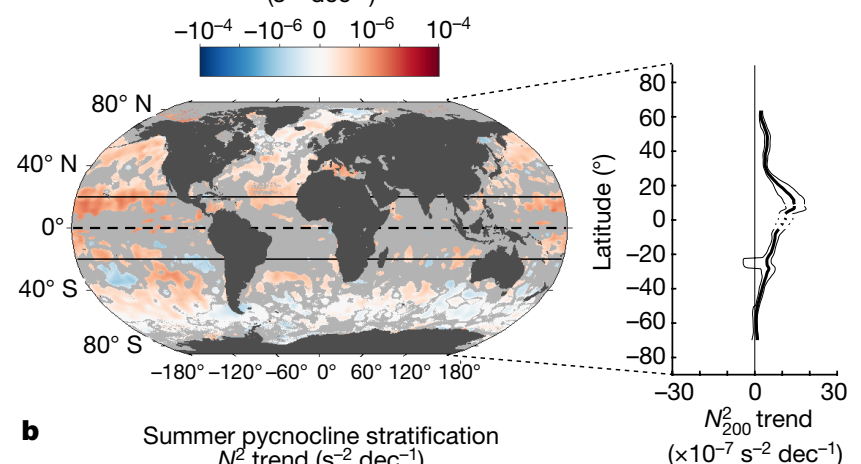

$$
\begin{aligned}
& \text { b Summer pycnocline stratification } \\
& N^{2} \text { trend }\left(\mathrm{s}^{-2} \mathrm{dec}^{-1}\right) \\
& -10^{-4}-10^{-6} 0 \text { 10 } \\
& \hline-6
\end{aligned}
$$

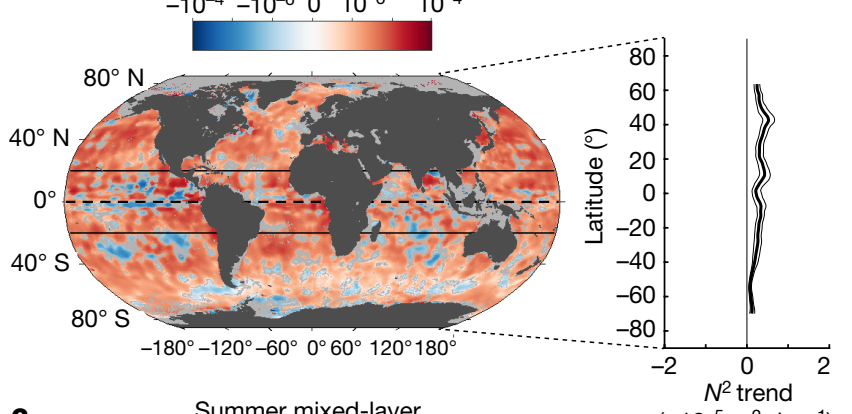

c $\left(\times 10^{-5} \mathrm{~s}^{-2} \mathrm{dec}^{-1}\right)$

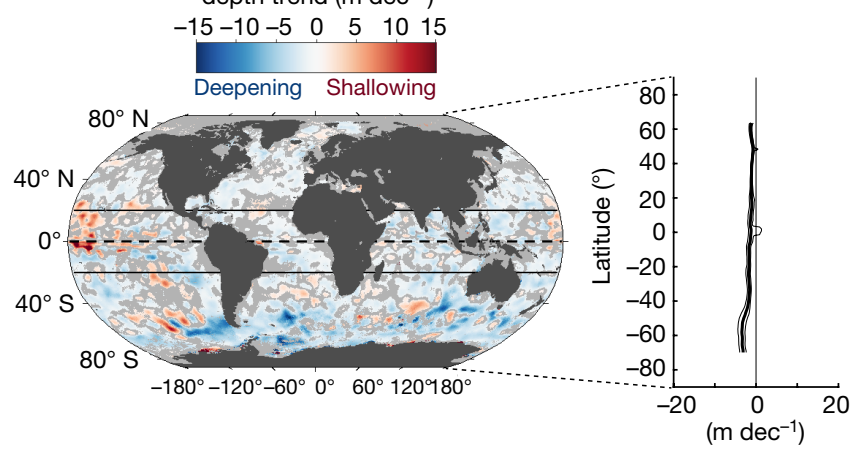

Fig. $3 \mid$ 1970-2018 trends in summer upper-ocean stratification and mixed-layer depth. a, b, Maps of the 1970-2018 summer 0-200 m (a; $N_{200}^{2}$ trend in $\mathrm{s}^{-2} \mathrm{dec}^{-1}$ ) and pycnocline stratification $\left(\mathbf{b} ; N^{2}\right.$ trend in $\left.\mathrm{s}^{-2} \mathrm{dec}^{-1}\right)$ trends, along with the zonal-median value (thick black line) and 33th-66th percentile (thin black line). Regions with no significant trend (that is, a trend lower than the standard error; see Methods) are shaded in grey on the map. c, As in a, b, but for the summer mixed-layer trend in $\mathrm{m} \mathrm{dec}^{-1}$ (note that mixed-layer deepening is shown as a negative trend).

control of stratification by temperature is particularly obvious in the evaporation-dominated regions of the subtropics and mid-latitudes. These are characterized by high climatological upper-ocean salinity (higher than the global mean) and exhibit an unstable vertical salinity gradient (saltier waters overlying fresher waters), for which the vertical temperature gradient overcompensates to attain a state of upper-ocean stability (Fig. 4a, b). By contrast, high latitudes are precipitation-dominated regions and contain very cold surface waters, such that upper-ocean stability is almost entirely established by the vertical salinity gradient (Fig. 4a, b). Interestingly, the observed change in pycnocline stratification results from an amplification of this climatological regional pattern: areas with an unstable salinity profile in the climatological pattern have further de-stabilized in the past 50 years, and areas with a stable salinity profile in the climatological pattern have further stabilized in the past 50 years. These changes in vertical salinity gradient are consistent with the now widely documented paradigm of

\begin{tabular}{|c|c|c|c|}
\hline$\left(\% \mathrm{dec}^{-1}\right)$ & Choice 1 & Choice 2 & Mean \\
\hline$N_{200}^{2}$ & $1.5 \pm 0.2$ & $1.1 \pm 0.3$ & $1.3 \pm 0.3$ \\
\hline$N^{2}$ & $9.5 \pm 4.4$ & $8.3 \pm 0.9$ & $8.9 \pm 2.7$ \\
\hline MLD & $-2.6 \pm 0.1$ & $-3.2 \pm 0.9$ & $-2.9 \pm 0.5$ \\
\hline
\end{tabular}
a contemporary acceleration of Earth's hydrological cycle, as a result of
Table 1 | Global mean percentage change

Global mean percentage change and the associated standard errors of the mean for $N_{200}^{2}, N^{2}$ and the mixed-layer depth (MLD). Local trend estimates at each grid point are divided by the local climatological mean value, and the global mean and standard error of the global mean are then computed. Standard error is computed by propagating the local standard error produced by the regression method (see Methods, Extended Data Fig. 4).

which fresh oceanic regions have become fresher and salty regions have become saltier ${ }^{31-34}$. In turn, the contribution of the vertical temperature gradient to increased pycnocline stratification has consistently increased worldwide in response to global ocean surface warming ${ }^{1}$. An exception is the subpolar Southern Ocean, where modest change in the vertical temperature gradient is in accord with reports of weak warming, or even slight cooling, having occurred in this region over recent decades ${ }^{35,36}$ (see Extended Data Fig. 7). Viewed overall, the consistency of our results with previous assessments of changes in Earth's surface temperature and hydrological cycle endorses the robustness of our analytical approach. More quantitatively, our method produces estimates of mixed-layer temperature change that are in accord with other widely recognized and used sea-surface temperature products (see Methods, Extended Data Fig. 7).

\section{Changes in mixed-layer depth}

The global-scale pycnocline stratification strengthening is, in principle, well understood, because it is predicted to arise from ocean surface warming associated with recent climate change. By contrast, the evolution of the mixed-layer depth might be expected to be more complex, as it is shaped by a delicate interplay between stabilizing and de-stabilizing forcings. So far, it has been generally assumed that there is a direct association between increasing pycnocline stratification and mixed-layer shoaling ${ }^{5-7}$. Here we show that, counter-intuitively, this commonly accepted assumption is at odds with observed changes in upper-ocean structure over the past 50 years. Our analysis reveals that the summertime strengthening of pycnocline stratification has occurred in association with a worldwide deepening (rather than shoaling) of the summer mixed layer at a rate of several metres per decade, ranging from $5 \mathrm{~m} \mathrm{dec}^{-1}$ to $10 \mathrm{~m} \mathrm{dec}^{-1}$ depending on the region (Fig. $3 \mathrm{c}$ ). The multi-decadal deepening is remarkably consistent globally, with most intense deepening in the Southern Ocean, within the $40-60^{\circ} \mathrm{S}$ latitude band containing the deepest climatological mixed layers (Fig. 2e). Our results present some local patchiness in the Southern Ocean. Data sparseness in the Southern Ocean can be a limitation in computing local/regional trends, which can explain some of this patchiness, although basin-scale diagnostics in the Southern Ocean are robust to data sparseness (see further analysis on that aspect in Supplementary Information). Overall, the global-mean per cent change (percentage of the local climatogical mean) is $-2.9 \pm 0.5 \% \mathrm{dec}^{-1}$ (mean \pm one standard error; Table 1 ; by convention, negative change refers to deepening). We note that these rates of change are not artificially generated by variations in the global ocean-observing system-for example, with the launch of the Argo programme in the 2000s (see Methods, Extended Data Figs. 8, 9)-and are not only due to the largest changes in the Southern Ocean (see Supplementary Information), but do reflect a widespread mixed-layer deepening. Changes in mixed-layer depth, pycnocline stratification and 0-200 m stratification are dynamically linked, and it is reassuring that all of the global-mean rates of change estimated in this study are mutually consistent (see Methods). Our diagnostics of trends in winter mixed-layer depth must be treated 

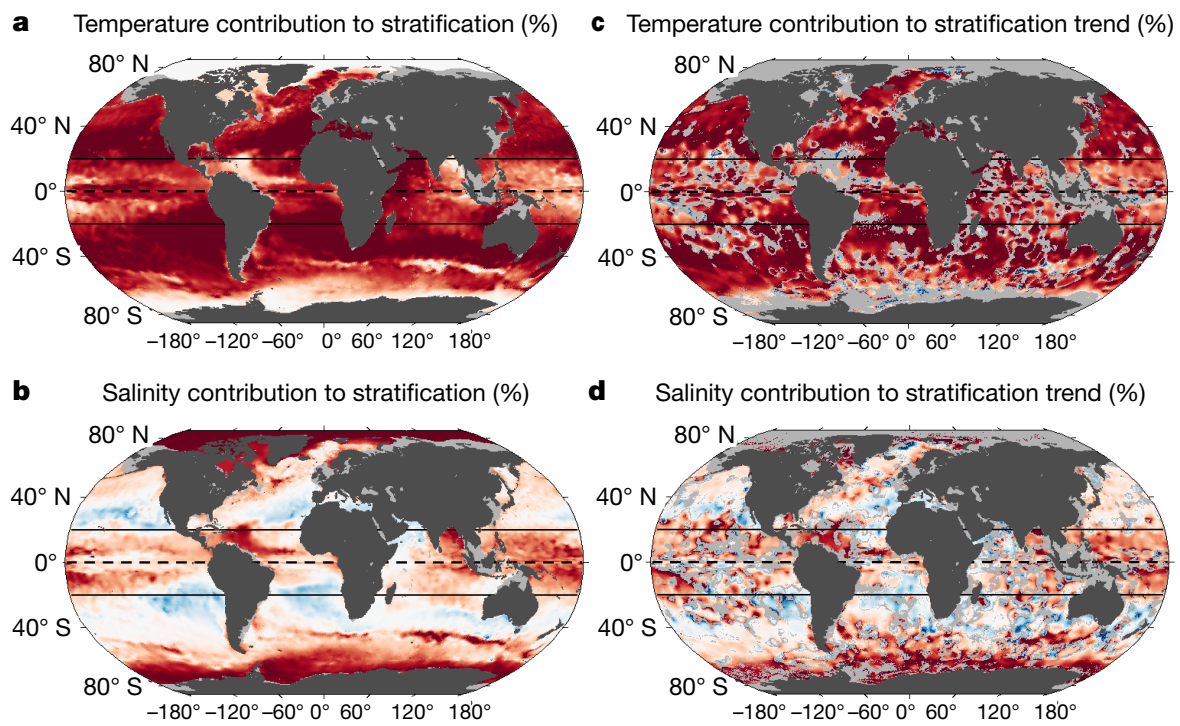

d Salinity contribution to stratification trend (\%)

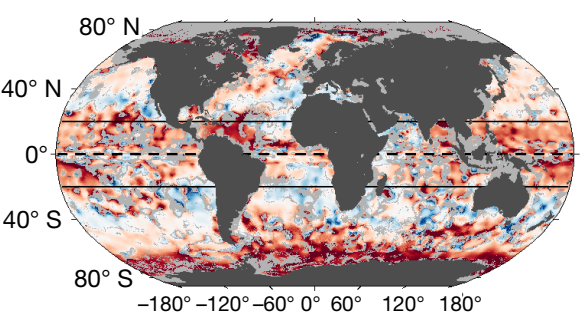

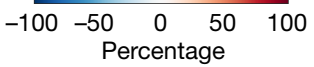

Fig. 4 | Temperature and salinity contributions to pycnocline stratification and its change. a, b, Per cent contribution of temperature (a) and salinity (b) to the summer climatological pycnocline stratification shown in Fig. 2a. Per cent contribution of temperature (c) and salinity (d) to the summer climatological pycnocline stratification trend shown in Fig. 3a. Regions with no significant trend (that is, a trend lower the standard error; see Methods) are shaded in grey in $\mathbf{c}, \mathbf{d}$. with caution, because they are based on shorter time series and may be affected by sub-sampling of large intra-seasonal and interannual variability. Nevertheless, they concur with the summer results: there is a global-scale deepening of the winter mixed layer, although with a suggestion of regional winter shoaling in the Pacific sector of the Southern Ocean (see Methods, Extended Data Figs. 5, 6).

It is helpful to visually examine time series of the evolution of upper-ocean structure on regional scales in order to increase our confidence in the observed large-scale changes. We therefore produce annual median percentage anomaly (percentage anomaly from the local seasonal climatology) diagnostics using all available individual observations, and fit a linear-regression model to the annual medians. This method has the advantage of being grounded on individual observations (by avoiding the gridding procedure); however, although it allows visualization of regional time series, it may induce regional biases owing to the uneven spatio-temporal sampling, as well as averaging out of the largest changes (Fig. 5). The locally gridded linear-regression trends presented above (Fig. 3) are more robust in this regard. Focusing on the North Atlantic basin in $30-60^{\circ} \mathrm{N}$, on the North Pacific basin in $30-60^{\circ} \mathrm{N}$, or on the Southern Ocean in the circumpolar band that contains the deepest summer mixed layers invariably confirms our central result of a strengthening of pycnocline stratification occurring in tandem with a mixed-layer deepening (Fig. 5). Even with this statistically less robust approach, we find a basin-scale rate of change that is quantitatively consistent with the more robust approach presented above: increasing pycnocline stratification at a rate of $8.1 \pm 4.1 \% \mathrm{dec}^{-1}$ in the Southern Ocean, $6.7 \pm 1.5 \% \mathrm{dec}^{-1}$ in the North Atlantic and $7.5 \pm 1.7 \% \mathrm{dec}^{-1}$ in the North Pacific, and a deepening mixed layer at a rate of $-3.4 \pm 1.5 \% \mathrm{dec}^{-1}$ in the Southern Ocean (see a further analysis on the sensitivity of this trend in Supplementary Information), $-1.5 \pm 0.9 \% \mathrm{dec}^{-1}$ in the North Atlantic and $-3.6 \pm 0.9 \% \mathrm{dec}^{-1}$ in the North Pacific. Although a 50-year, large-scale increase in the mixed-layer depth has not been previously documented, one recent study ${ }^{17}$ reported a deepening of the mixed layer at three selected sites in the North Atlantic and North Pacific between 1990 and 2015, at rates ranging from 1 to $8 \mathrm{~m} \mathrm{dec}^{-1}$, which are consistent with our results $\left(5-10 \mathrm{~m} \mathrm{dec}^{-1}\right)$.
Given the increasing pycnocline stratification, the observed deepening of the mixed layer must have necessarily been driven by an intensification of surface turbulence overcoming the increased stability below the mixed layer. Surface turbulence can be generated by a range of processes, including surface buoyancy fluxes (giving rise to convective mixing), wind-driven mechanical mixing, wave breaking, wave-generated Langmuir turbulence or internal waves, and wind- or buoyancy-forced submesoscale instabilities at upper-ocean fronts ${ }^{27,37,38}$ (see Methods). Under the current climate change, variations in surface buoyancy fluxes act to suppress turbulence by increasing the buoyancy of mixed-layer waters, as indicated by Fig. 4, so they cannot account for the observed mixed-layer deepening. Even in regions that have experienced a salinity-driven destabilization, arguably due to an increased evaporation (blue regions in Fig. 4d), our results show that the vertical density stratification has increased (Fig. 4a), because the increase in temperature-driven stability has overcompensated the salinity-driven destabilization (Fig. 4a). As a consequence, the body of available evidence suggests that changes in air-ice-sea heat or freshwater fluxes cannot have driven a destabilization of the upper ocean, which would have led to a deepening mixed layer. Intensification of mechanical turbulence overcoming the increased stability is needed. Observations of such turbulence are, however, limited to a number of process-oriented studies, and there is currently no physically consistent, observation-based dataset available to assess long-term change in upper-ocean turbulence. Instead, we use scaling arguments to demonstrate that our current theoretical understanding of mixed-layer physics is potentially compatible with the mixed-layer deepening and increased stratification that have occurred in recent decades. This theoretical framework suggests that the mixed-layer deepening documented here may plausibly have been driven by a global intensification of the wind field, including its high-frequency component, for which there is a range of emerging evidence ${ }^{10,11,39}$ (see Methods). The influence of invigorated winds may have been exerted through one or several of: internal-wave-driven turbulence linked to high-frequency winds ${ }^{38}$, wave-generated Langmuir turbulence ${ }^{37}$, and submesoscale instabilities at upper-ocean fronts ${ }^{27}$. We note, however, that the contribution of the latter process is less clear, 


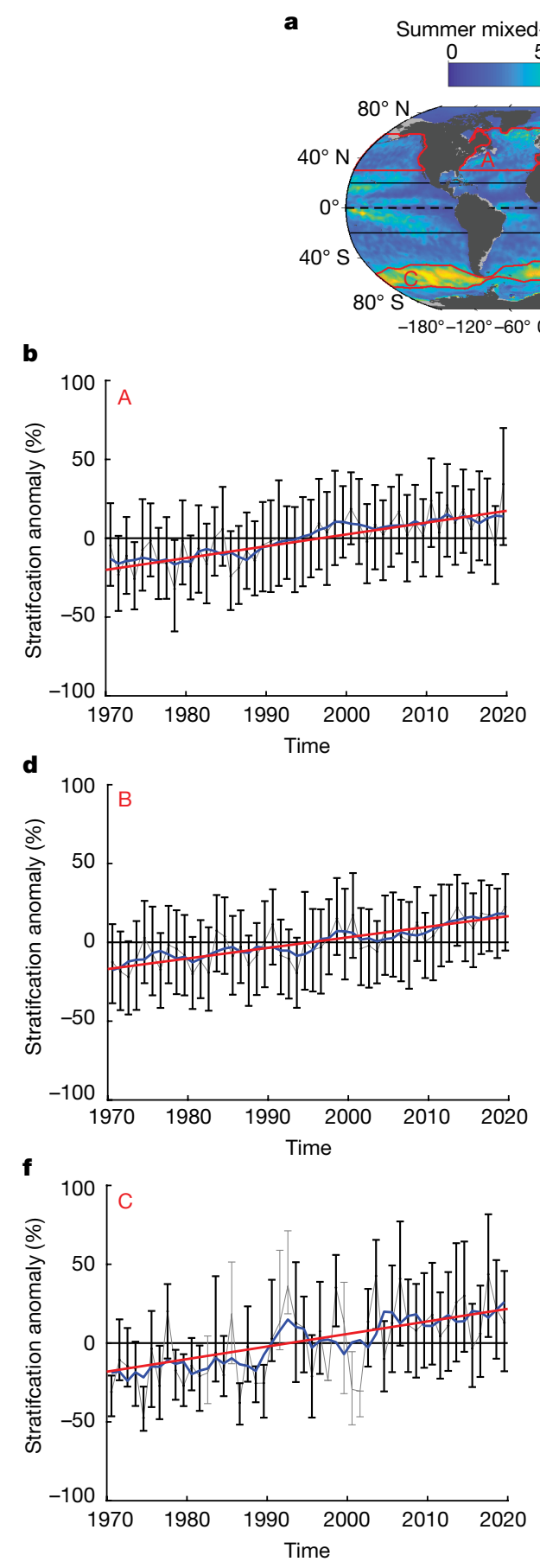

Fig. 5 | Regional time series of summer pycnocline stratification and mixed-layer depth anomaly. a, Summer climatological mixed-layer depth, as in Fig. 2e, with three specific regions of interest outlined by red contours: North Atlantic (A), North Pacific (B) and Southern Ocean (C). b-g, Summer stratification anomaly times series and associated trends for regions $\mathrm{A}(\mathbf{b})$, $B(\mathbf{d})$ and $C(\mathbf{f})$, and summer mixed-layer depth anomaly times series and associated trends for regions $\mathrm{A}(\mathbf{c}), \mathrm{B}(\mathbf{e})$ and $\mathrm{C}(\mathbf{g})$. Note that a negative depth anomaly refers to a deepening. Each times series panel shows: the annual

because submesoscales could also have a counteracting, mixed-layer shoaling effect that we do not consider here ${ }^{40,41}$ (see Methods).

\section{Conclusions}

Our findings carry important implications for our understanding of the impacts of global climate change on ocean circulation and marine
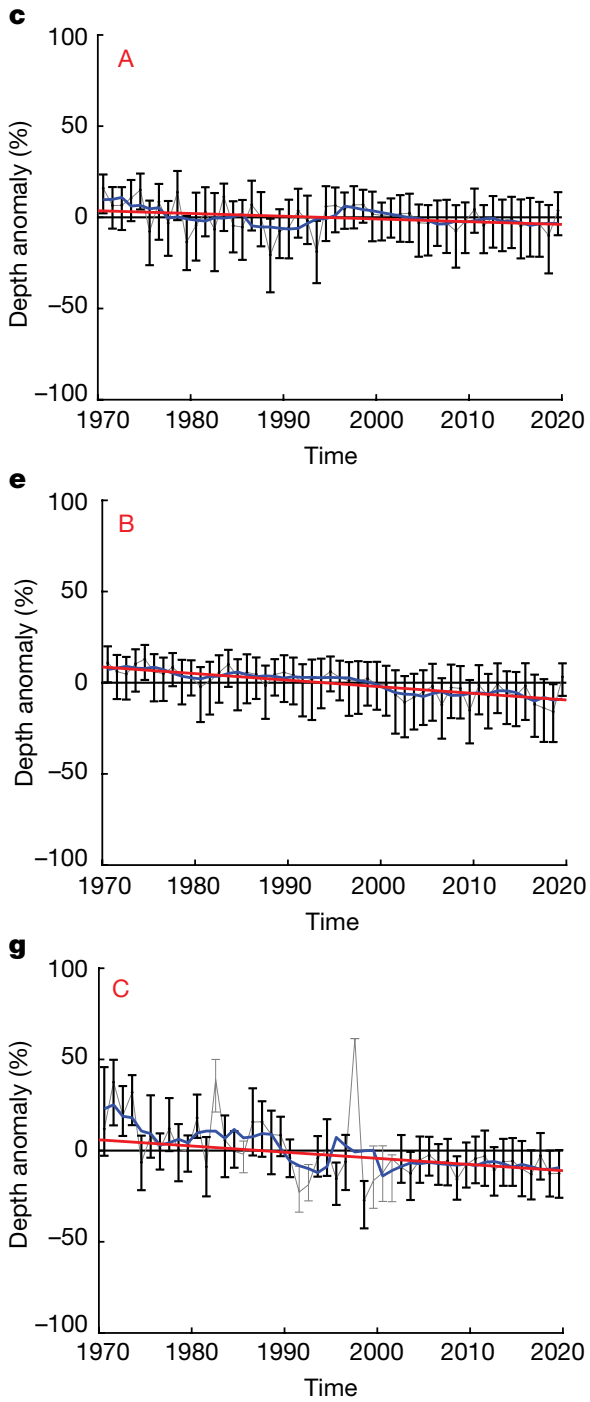

median percentage anomaly (thin grey line; from the local climatological seasonal cycle), computed for each individual observation; error bars referring to the 33th-66th percentile range of percentage anomaly-error bars are shown in black (grey) when more (fewer) than 50 data points are used in the annual statistics; the associated five-year smoothed median time series superimposed in blue; and a linear trend in 1970-2018, shown by the red line if greater than twice its standard error.

ecosystems. First, we have shown that, over the past five decades, all ocean basins have experienced a strengthening of summer pycnocline stratification, at a rate at least six times higher than previously reported $^{16,18,19}$. If the turbulent energy reaching the pycnocline had remained constant, such a change in stratification would bring about a large reduction in mixing between the upper and deep oceanic lay$\mathrm{ers}^{42}$. Weaker vertical mixing would probably result in a slowdown of 


\section{Article}

deep-ocean ventilation and oxygenation ${ }^{43}$ and substantially weaken upper-ocean nutrient recharge by mixing with deeper waters. Second, we have found that the surface mixed layer has deepened across much of the world ocean. This may possibly counteract the effects of a strengthened pycnocline stratification, as a deepening mixed layer would promote the upward transfer of poorly ventilated and oxygenated, and nutrient-enriched pycnocline waters. Such mixed-layer deepening could also affect near-surface temperature and salinity changes by increasing the volume of the surface layer, hence providing a climatic feedback mechanism ${ }^{2}$. Deepening of the summer mixed layer may also lead to a degradation of light conditions within the near-surface waters in which most primary producers live, thus negatively affecting the biological carbon pump ${ }^{5,6,15}$. A final consequence of the changes in pycnocline stratification and mixed-layer depth uncovered by our work is a shift in a range of fundamental dynamical properties of the ocean circulation that depend sensitively on upper-ocean stratification. These include ${ }^{42}$ : the first baroclinic Rossby radius of deformation ${ }^{44}$, which is the natural horizontal scale of oceanic boundary currents, eddies and fronts; the speed of propagation of baroclinic waves across ocean basins; and the vertical structure of oceanic gyres and coastal upwelling systems. To conclude, given their many ramifications for ocean circulation and climate, our results represent a critical benchmark for the evaluation of the current generation of Earth system models and highlight the need to maintain a global ocean-observing system that provides the necessary measurements to best inform on the scales of current changes in our oceans and help to shape relevant adaptation strategies and policies going forward.

\section{Online content}

Any methods, additional references, Nature Research reporting summaries, source data, extended data, supplementary information, acknowledgements, peer review information; details of author contributions and competing interests; and statements of data and code availability are available at https://doi.org/10.1038/s41586-021-03303-x.

1. Bindoff, N. L. et al. in IPCC Special Report on the Ocean and Cryosphere in a Changing Climate (eds Pörtner, H.-O. et al.) Ch. 5 (IPCC, 2019)

2. Frankignoul, C. \& Hasselmann, K. Stochastic climate models, part II application to sea-surface temperature anomalies and thermocline variability. Tellus 29, 289-305 (1977).

3. Bopp, L., Lévy, M., Resplandy, L. \& Sallée, J. Pathways of anthropogenic carbon subduction in the global ocean. Geophys. Res. Lett. 42, (2015).

4. Sverdrup, H. U. On conditions for the vernal blooming of phytoplankton. ICES J. Mar. Sci. 18, 287-295 (1953).

5. Behrenfeld, M. J. et al. Climate-driven trends in contemporary ocean productivity. Nature 444, 752-755 (2006)

6. Boyce, D. G., Lewis, M. R. \& Worm, B. Global phytoplankton decline over the past century. Nature 466, 591-596 (2010)

7. Polovina, J. J., Howell, E. A. \& Abecassis, M. Ocean's least productive waters are expanding. Geophys. Res. Lett. 35, L03618 (2008).

8. Li, G. et al. Increasing ocean stratification over the past half-century. Nat. Clim. Chang. 10 , $1116-1123$ (2020)

9. Yamaguchi, R. \& Suga, T. Trend and variability in global upper-ocean stratification since the 1960s. J. Geophys. Res. Oceans 124, 8933-8948 (2019).

10. Young, I. R. \& Ribal, A. Multiplatform evaluation of global trends in wind speed and wave height. Science 364, 548-552 (2019)

11. Young, I. R., Zieger, S. \& Babanin, A. V. Global trends in wind speed and wave height Science 332, 451-455 (2011).

12. Sprintall, J. \& Tomczak, M. Evidence of the barrier layer in the surface layer of the tropics. J. Geophys. Res. Oceans 97, 7305-7316 (1992).

13. Kataoka, T., Kimoto, M., Watanabe, M. \& Tatebe, H. Wind-mixed layer-SST feedbacks in a tropical air-sea coupled system: application to the Atlantic. J. Clim. 32, 3865-3881 (2019).

14. Sallée, J. B., Matear, R., Rintoul, S. R. \& Lenton, A. Localised subduction of anthropogenic carbon dioxide in the Southern Hemisphere oceans. Nat. Geosci. 5, 579-584 (2012).
15. Llort, J., Lévy, M., Sallée, J. B. \& Tagliabue, A. Nonmonotonic response of primary production and export to changes in mixed-layer depth in the Southern Ocean. Geophys. Res. Lett. 46, 3368-3377 (2019).

16. Pörtner, H.O. et al. Summary for policymakers. IPCC Special Report on the Ocean and Cryosphere in a Changing Climate (eds Pörtner, H.-O. et al.) (IPCC, 2019).

17. Somavilla, R., González-Pola, C. \& Fernández-Diaz, J. The warmer the ocean surface, the shallower the mixed layer. How much of this is true? J. Geophys. Res. Oceans 122 7698-7716 (2017).

18. Capotondi, A., Alexander, M. A., Bond, N. A., Curchitser, E. N. \& Scott, J. D. Enhanced upper ocean stratification with climate change in the CMIP3 models. J. Geophys. Res. Oceans 117, C04031 (2012).

19. Helm, K. P., Bindoff, N. L. \& Church, J. A. Observed decreases in oxygen content of the global ocean. Geophys. Res. Lett. 38, L23602 (2011).

20. Kwiatkowski, L. et al. Twenty-first century ocean warming, acidification, deoxygenation, and upper-ocean nutrient and primary production decline from CMIP6 model projections. Biogeosciences 17, 3439-3470 (2020)

21. Pellichero, V., Sallée, J.-B., Schmidtko, S., Roquet, F. \& Charrassin, J.-B. The ocean mixed layer under Southern Ocean sea-ice: seasonal cycle and forcing. J. Geophys. Res. Oceans 122, 1608-1633 (2017).

22. Treasure, A. M. et al. Marine mammals exploring the oceans pole to pole: a review of the MEOP consortium. Oceanography 30, 132-138 (2017).

23. Schmidtko, S., Johnson, G. C. \& Lyman, J. M. MIMOC: a global monthly isopycnal upper-ocean climatology with mixed layers. J. Geophys. Res. Oceans 118, 1658-1672 (2013).

24. Schmidtko, S., Heywood, K. J., Thompson, A. F. \& Aoki, S. Multidecadal warming of Antarctic waters. Science 346, 1227-1231 (2014).

25. Schmidtko, S., Stramma, L. \& Visbeck, M. Decline in global oceanic oxygen content during the past five decades. Nature 542, 335-339 (2017).

26. Kuusela, M. \& Stein, M. L. Locally stationary spatio-temporal interpolation of argo profiling float data. Proc. R. Soc. Lond. A 474, 20180400 (2018).

27. Buckingham, C. E. et al. The contribution of surface and submesoscale processes to turbulence in the open ocean surface boundary layer. J. Adv. Model. Earth Syst. 11, 4066-4094 (2019).

28. de Boyer Montégut, C., Madec, G., Fischer, A. S., Lazar, A. \& ludicone, D. Mixed layer depth over the global ocean: an examination of profile data and a profile-based climatology. J. Geophys. Res. 109, C12003 (2004)

29. Sallée, J. B., Speer, K. G. \& Rintoul, S. R. Zonally asymmetric response of the Southern Ocean mixed-layer depth to the Southern Annular Mode. Nat. Geosci. 3, 273-279 (2010).

30. Holte, J., Talley, L. D., Gilson, J. \& Roemmich, D. An Argo mixed layer climatology and database. Geophys. Res. Lett. 44, 5618-5626 (2017).

31. Rhein, M. et al. in Climate Change 2013: The Physical Science Basis. Contribution of Working Group I to the Fifth Assessment Report of the IPCC (eds Stocker, T. F. et al.) 255316 (Cambridge Univ. Press, 2013).

32. Durack, P. J. \& Wijffels, S. E. Fifty-year trends in global ocean salinities and their relationship to broad-scale warming. J. Clim. 23, 4342-4362 (2010).

33. Durack, P. J., Wijffels, S. E. \& Matear, R. J. Ocean salinities reveal strong global water cycle intensification during 1950 to 2000. Science 336, 455-458 (2012).

34. Bindoff, N. L. et al. in Climate Change 2013: The Physical Science Basis. Contribution of Working Group I to the Fifth Assessment Report of the IPCC (eds Stocker, T. F. et al.) 867-952 (Cambridge Univ. Press, 2013).

35. Armour, K. C., Marshall, J., Scott, J. R., Donohoe, A. \& Newsom, E. R. Southern Ocean warming delayed by circumpolar upwelling and equatorward transport. Nat. Geosci. 9 549-554 (2016)

36. Marshall, J. et al. The ocean's role in the transient response of climate to abrupt greenhouse gas forcing. Clim. Dyn. 44, 2287-2299 (2015)

37. Belcher, S. E. et al. A global perspective on Langmuir turbulence in the ocean surface boundary layer. Geophys. Res. Lett. 39, L18605 (2012).

38. Barkan, R., Winters, K. B. \& McWilliams, J. C. Stimulated imbalance and the enhancement of eddy kinetic energy dissipation by internal waves. J. Phys. Oceanogr. 47, 181-198 (2017).

39. Hu, S. et al. Deep-reaching acceleration of global mean ocean circulation over the past two decades. Sci. Adv. 6, eaax7727 (2020).

40. Siegelman, L. et al. Enhanced upward heat transport at deep submesoscale ocean fronts. Nat. Geosci. 13, 50-55 (2020)

41. Su, Z., Wang, J., Klein, P., Thompson, A. F. \& Menemenlis, D. Ocean submesoscales as a key component of the global heat budget. Nat. Commun. 9, 775 (2018).

42. Gill, A. E. \& Niiler, P. P. The theory of the seasonal variability in the ocean. Deep-Sea Res. Oceanogr. Abstr. 20, 141-178 (1973).

43. Oschlies, A., Brandt, P., Stramma, L. \& Schmidtko, S. Drivers and mechanisms of ocean deoxygenation. Nat. Geosci. 11, 467-473 (2018)

44. Killworth, P. D., Chelton, D. B. \& de Szoeke, R. A. The speed of observed and theoretical long extratropical planetary waves. J. Phys. Oceanogr. 27, 1946-1966 (1997).

Publisher's note Springer Nature remains neutral with regard to jurisdictional claims in published maps and institutional affiliations.

(c) The Author(s), under exclusive licence to Springer Nature Limited 2021 


\section{Methods}

\section{Data sources and density}

Three distinct types of observation are considered in this study, in order to maximize spatial and temporal coverage. First, we use vertical conductivity-temperature-depth (CTD) profiles obtained from ship campaigns during the period 1970-2018 (Extended Data Fig. 2b). We use 'high-resolution CTD' data (that is, vertical resolution of less than $2 \mathrm{~m}$ ) from the NOAA World Ocean Database (https://www.nodc. noaa.gov/OC5/SELECT/dbsearch/dbsearch.html) and augment it with profiles obtained from the PANGAEA database (https://www.pangaea. $\mathrm{de} /$ ). We use only profiles that have an 'accepted profile' quality-control flag (that is, best quality only) and that contain information on position, date, temperature and salinity. These amount to more than 1.37 million profiles (Extended Data Fig. 2b). We note that earlier observations might have been sampled by less technologically mature salinity sensors $^{45}$. However, whereas salinity in the 1950 s or 1960 s could be associated with errors of the order of $10^{-2} \mathrm{~g} \mathrm{~kg}^{-1}$, the typical salinity accuracy in the 1970 s or 1980 s was, although inferior to today's, of the order of several times $10^{-3} \mathrm{~g} \mathrm{~kg}^{-1}$ (ref. ${ }^{46}$ ). This is unimportant for detecting a density shift of $0.03 \mathrm{~kg} \mathrm{~m}^{-3}$ (see Methods section 'Definition of mixed-layer depth and pycnocline stratification'), which typically corresponds to a salinity change of $\sim 0.04 \mathrm{~g} \mathrm{~kg}^{-1}$. The vertical resolution of the profiles could be a more important factor in accurately describing the mixed layer, but we account for it in our uncertainty estimates (see Methods section 'Definition of mixed-layer depth and pycnocline stratification').

This ship-based hydrographic database ${ }^{47}$ is complemented by float data from the Argo international programme (http://www.argo.ucsd. edu/). The Argo programme commenced in 2000 and has crucially increased the number of ocean observations acquired every year over the world ocean ${ }^{48,49}$. All publicly available profiles up to the end of 2018 that contain information on position, date, temperature and salinity are used. We use only profiles that have a quality flag of 'good data' (that is, best quality only), as well as delayed time-calibrated values if provided. These amount to more than 1.39 million profiles (Extended Data Fig. 2c).

Finally, we also consider profiles from marine mammal-borne sensors, obtained through the Marine Mammals Exploring the Oceans Pole to Pole programme (MEOP) (http://www.meop.net/) ${ }^{22}$. We use a calibrated dataset ${ }^{50}$, and we consider only profiles that have a quality control flag of 'good data' (that is, best quality only), are adjusted after the delayed time calibration provided by MEOP, and contain information on position, date, temperature and salinity. These amount to more than 480,000 profiles (Extended Data Fig. 2 d).

These three types of observation are complementary in space and time. Ship-based observations are concentrated along repeated hydrographic sections or near coastlines (Extended Data Fig. 2b). Ship-based observations are a key dataset for our study, because they provide the longest time series. In turn, Argo float observations are more widely spread across ocean basins (Extended Data Fig. 2c) and less seasonally biased than ship-based observations. However, they are scarce in regions that are seasonally capped by sea ice, despite the recent growth of the under-ice Argo network. The instrumented marine mammal dataset provides measurements in the climatically important southern subpolar region, and to a lesser extent in the subtropics and high latitudes of the Northern Hemisphere (Extended Data Fig. 2d). Overall, the combination of these three datasets affords an unprecedented cover of the world ocean from pole to pole (Extended Data Fig. 2a).

In this work, we are interested in detecting long-term trends from this observing system. Therefore, one specific aspect that is important to our study is the long-term temporal coverage provided by the dataset. A metric of this coverage is the maximum time difference between available observations in $1^{\circ} \times 1^{\circ}$ longitude-latitude bins over the globe. In summer, most of the world ocean exhibits a maximum time difference exceeding 40 years, with some notable exceptions in parts of the eastern tropical and southern subtropical Pacific (Extended Data Fig. 2e). In winter, the maximum time difference is mostly larger than 40 years in the Northern Hemisphere, but generally closer to 20 years in the Southern Hemisphere, with exceptions near the coasts and along repeated hydrographic sections (Extended Data Fig. 2f). This maximum time difference metric indicates that summer trends will be better constrained than winter trends, and that the suitability of available observations for the detection of multidecadal trends is geographically variable. Close attention to this heterogeneity in data abundance is necessary when interpreting global-mean statistical analyses $^{51}$. Here, we investigate mapped (that is, region-specific) trends, consider trends in individual seasons and examine regional time series in order to overcome this issue.

\section{Definition of mixed-layer depth and pycnocline stratification}

The mixed layer is defined as the oceanic surface layer in which density is nearly homogeneous with depth. A number of methods have been developed over the years to compute the mixed-layer depth from a given density, salinity or temperature profile ${ }^{28,52-54}$. Methods based on density, rather than temperature, profiles are usually more successful in detecting the mixed-layer base $\mathrm{e}^{30,54,55}$ and have become a standard for defining the mixed-layer depth. A range of methods applicable to density profiles have been proposed, on the basis of, for example, a threshold density deviation from surface density, a density gradient threshold, or a piece-wise fit to the density profile. A recently developed hybrid approach proposes the use of a combination of these different methods and appears to work well worldwide ${ }^{30}$. In this study, we adopt the method based on a threshold density deviation from surface density ${ }^{28,55}$. Specifically, we define the mixed-layer depth as the depth at which the potential density referenced to the surface, $\sigma_{0}$, exceeds by a threshold of $0.03 \mathrm{~kg} \mathrm{~m}^{-3}$ the density of the water at $10 \mathrm{~m}, \sigma_{0}(z=-H)=\sigma_{0}(z=-10 \mathrm{~m})+0.03 \mathrm{~kg} \mathrm{~m}^{-3}$, with $H$ the mixed-layer depth. We choose this threshold because it has been shown to robustly detect the base of the mixed layer in various regions of the world ${ }^{28,54,55}$. Further, this approach produces, overall, nearly identical diagnostics of mixed-layer depth to those from more complex methods ${ }^{30}$. At any rate, we acknowledge this methodological sensitivity by quantifying the uncertainty in our mixed-layer results as the standard deviation of the values computed from the three independent density-based procedures proposed by Holte and Talley ${ }^{21,54}$. This approach allows us to define an overall uncertainty estimate, including uncertainties associated with temperature, pressure and conductivity sensor performance, as well as uncertainties associated with vertical resolution ${ }^{21}$. We reject all mixed-layer depth estimates from density profiles for which the standard deviation of results from the three procedures is greater than $25 \%$ of their mean value. If the computed standard deviation is smaller than the vertical resolution of the individual profile, the uncertainty is set to the vertical resolution-that is, $2 \mathrm{~m}$ for ship-based CTD data, $10 \mathrm{~m}$ for Argo profiles and $20 \mathrm{~m}$ for instrumented marine mammal profiles. The resulting uncertainty is then propagated into the gridding method as contributing to the variance associated to each observation.

Seasonal pycnocline stratification is defined as the squared buoyancy frequency computed from the density gradient over the 15-m layer directly below the mixed-layer base:

$$
N^{2}=-\left.\frac{g}{\rho} \frac{\partial \sigma_{0}}{\partial z}\right|_{-H \geq z \geq-H-15},
$$

where $g$ is the gravitational acceleration. The squared buoyancy frequency, $N^{2}$, is expressed in $\mathrm{s}^{-2}$.

The pycnocline stratification can be expressed, to a first approximation, as a linear combination of distinct temperature and salinity contributions $^{42}$ (see Fig. 4): 


$$
\begin{aligned}
& N^{2}=N_{\mathrm{T}}^{2}+N_{\mathrm{S}}^{2} \\
& \text { with } N_{\mathrm{S}}^{2}=\left.g \beta \frac{\partial S}{\partial z}\right|_{-H \geq z \geq-H-15} \text { and } N_{\mathrm{T}}^{2}=-\left.g \alpha \frac{\partial T}{\partial z}\right|_{-H \geq z \geq-H-15},
\end{aligned}
$$

where $\beta$ is the haline contraction coefficient and $\alpha$ is the thermal expansion coefficient.

\section{Mapping method for computing climatologies and associated trends}

The pycnocline stratification, mixed-layer depth and associated uncertainties are computed for each profile in our database. We then produce gridded maps of climatological mean fields and trends, calculated as local linear regressions of individual profiles around a grid point. We adopt a regular $0.5^{\circ} \times 0.5^{\circ}$ longitude-latitude grid. The method for computing a mean field and the associated long-term trend involves: (i) defining a spatial distance metric; (ii) selecting individual profiles that are close in space and time to a given grid point for a specific month; and (iii) producing a local generalized least-squares linear regression. These steps are described in turn in this section. We then consider the impact of the modelling choices. The associated uncertainties are discussed in Methods section 'Robustness and uncertainty quantification'.

Defining a distance metric. For each grid point, we compute the distance, $\Delta d_{i}$, separating each individual observation, $i$, from the grid point. We use a distance that follows bathymetric contours. In the ocean, near-conservation of potential vorticity translates into water particle pathways that tend to follow bathymetric contours, constraining all quantities from surface to depth ${ }^{56-58}$. We therefore construct a distance that follows this along-pathway constraint, using the fast marching method described in Schmidtko et al. ${ }^{23}$, which is based on Dijkstra's algorithm ${ }^{59}$. We refer the reader to Schmidtko et al. ${ }^{23}$ for more details on the fast marching method.

Data selection. For each grid point and each month of the year, a distance weight, $w_{i}$, is ascribed to each individual observation, $i$, with a conventional Gaussian form accounting for the along-path distance $\left(\Delta d_{i}\right)$ and time difference from the given month $\left(\Delta \tau_{i}\right)$ :

$$
w_{i}=\mathrm{e}^{-\left[\left(\frac{\Delta d_{i}}{L_{d}}\right)^{2}+\left(\frac{\Delta \tau_{i}}{L_{\tau}}\right)^{2}\right]},
$$

with $L_{\tau}$ and $L_{d}$ chosen as fixed length scales representing the resolution at which we wish to map our field, $L_{\tau}=1.5$ months and $L_{d}=330 \mathrm{~km}$. Using this distance weight, the 300 closest data points (that is, 300 largest values of $w_{i}$ ) are selected to proceed to a linear-regression fit for the given grid point and month.

Local generalized least-squares regression. Based on the selected observations, we compute, for each grid point and month, a local generalized least-squares regression solving $y=X \beta+\varepsilon$, where $y$ is the observed quantity (for example, mixed-layer depth, stratification), $\beta$ are the unknown regression coefficients, and $\varepsilon$ are the associated errors, which are assumed to be Gaussian with mean zero and covariance matrix $\operatorname{cov}(\varepsilon)=\Omega$. The resulting regression depends on the choice of the design matrix $X$, as well as the covariance matrix $\Omega$. To investigate the sensitivity of our results to these choices, we use two different covariance matrices $\Omega$.

We choose $X$ to regress a constant and a linear time trend term, $y_{i}=\beta_{0}+\beta_{1}\left(t_{i}-t_{0}\right)+\varepsilon_{i}$, where $t_{i}$ is the time of the $i$ th observation and $t_{0}$ is a reference time for the climatology, set to year 2000. (We also explored the sensitivity of our results to using a second choice for $X$ to regress a constant, a linear time trend, as well as linear and quadratic spatial terms around the grid point; all results and conclusions of the paper remained virtually unchanged.) In this model, the estimate of the climatological mean for the given grid point and month is given by $\beta_{0}$ and the estimate of the time trend by $\beta_{1}$, and the uncertainties are quantified as the standard errors of these local regression coefficients.

For the covariance matrix $\Omega$, we use on the diagonal the local total variance $\omega_{i}$, composed of a large-scale 'Gaussian process' variance $\phi$, a fine-scale 'nugget' variance $\sigma_{n}^{2}$ and the variance associated with the observation uncertainty $\sigma_{m, i}^{2}$. To localize the least-squares fit in space and time, we also include the distance weight to the grid point, $w_{i}$, leading us to perform a weighted fit based on the effective variances:

$$
\widetilde{\omega}_{i}=\frac{\omega_{i}}{w_{i}}=\frac{1}{w_{i}}\left(\phi+\sigma_{n}^{2}+\sigma_{m, i}^{2}\right)
$$

The observation uncertainty $\sigma_{m, i}^{2}$ is defined in Methods section 'Definition of mixed-layer depth and pycnocline stratification'. The Gaussian process variance $\phi$ and the nugget variance $\sigma_{n}^{2}$ are estimated, along with the spatial and temporal decorrelation scales $\left(\lambda_{d}\right.$ and $\lambda_{t}$, respectively), for each grid point and month of the year using a maximum-likelihood estimator based on the 300 selected observations, following the locally stationary Gaussian process approach presented in Kuusela and Stein ${ }^{26}$. The initial estimate of the mean field required by the Kuusela-Stein method is obtained by performing a local weighted regression with the weights $w_{i}$ and the model $y_{i}=\beta_{0}+\varepsilon_{i}$.

Our first choice of covariance matrix, $\Omega_{1}$, is based on considering $\omega_{i}$ for the individual observations but assuming no covariance between the observations. With weights included, this yields effective covariance $\widetilde{\Omega}_{1}=\operatorname{diag}(\widetilde{\omega})$, that is, a diagonal matrix with diagonal elements being $\widetilde{\omega}_{i}$. Our second choice of covariance matrix entails including, in addition to the diagonal elements of $\Omega_{1}$, covariances between the individual observations in the off-diagonal elements, which we compute as:

$$
\omega_{i j}=\phi \mathrm{e}^{-\sqrt{\left(\frac{\Delta d_{i j}}{\lambda_{d}}\right)^{2}+\left(\frac{\Delta t_{i j}}{\lambda_{t}}\right)^{2}}},
$$

with $\Delta d_{i j}$ the spatial distance between the two observations $(i, j)$ computed using the fast marching algorithm; $\Delta t_{i j}$ the time difference of the acquisition of the two observations $(i, j)$; and $\lambda_{d}$ and $\lambda_{t}$ the spatial and temporal decorrelation scales, respectively, estimated from the observations as described above. The resulting covariance matrix, $\Omega_{2}$, is then composed of $\omega_{i j}$ for the elements outside the diagonal, and of $\omega_{i i}=\omega_{i}$ for the elements on the diagonal. The corresponding effective covariance $\widetilde{\Omega}_{2}$ has elements:

$$
\widetilde{\omega}_{i j}=\frac{\omega_{i j}}{\sqrt{w_{i} w_{j}}}
$$

We note that using a non-Euclidean distance metric to compute $\Delta d_{i j}$ in equation (5) can in principle affect the positive definiteness of $\Omega_{2}$. However, we checked for this during our calculations and did not observe any issues with positive definiteness.

The generalized least-squares regression estimates $\beta=\left(\beta_{0}, \beta_{1}\right)^{\mathrm{T}}$ and their associated covariances may be written as:

$$
\hat{\beta}=\left(X^{\mathrm{T}} \widetilde{\Omega}_{i}^{-1} X\right)^{-1} X^{\mathrm{T}} \widetilde{\Omega}_{i}^{-1} y
$$

and

$$
\operatorname{cov}(\hat{\beta})=\left(X^{\mathrm{T}} \widetilde{\Omega}_{i}^{-1} X\right)^{-1} X^{\mathrm{T}} \widetilde{\Omega}_{i}^{-1} \operatorname{cov}(y) \widetilde{\Omega}_{i}^{-1} X\left(X^{\mathrm{T}} \widetilde{\Omega}_{i}^{-1} X\right)^{-1}
$$

where $i=1,2$ and $\operatorname{cov}(y)=\operatorname{cov}(\varepsilon)$ is the covariance matrix $\Omega_{i}$ without the weight terms. 
The final winter/summer maps are obtained as averages of the relevant three-month maps. Acknowledging that the three maps are strongly correlated, the standard error of the average is computed as the average of the individual standard errors, which serves as a conservative estimate of the desired standard error. Standard errors of the percentage changes $\beta_{1} / \beta_{0}$ are obtained by propagating the standard errors and covariance of both the trend $\beta_{1}$ and the climatological $\operatorname{mean} \beta_{0}$.

Sensitivity to modelling choices. We produce two solutions based on the following local regressions:

- Choice1 (covariance between observations): $y=X \beta+\varepsilon$, with $\operatorname{cov}(\varepsilon)=\Omega_{2}$ - Choice 2 (no covariance between observations): $y=X \beta+\varepsilon$, with $\operatorname{cov}(\varepsilon)=\Omega_{1}$.

The resulting summer and winter mixed-layer depth mean fields, the 1970-2018 summer mixed-layer depth and pycnocline stratification trends and the standard errors of the trends for each of the two choices are shown in Extended Data Figs. 3, 4. Small local differences, consistent with the anticipated behaviour of the regression model, are observed between the different choices. In particular, the off-diagonal covariance elements primarily affect the uncertainties and less so the point estimates. However, the main global and regional patterns remain unchanged across the two methods, for all of the mean, trend and standard error estimates, providing great confidence in the robustness of our results. In the main text, we present results from Choice 1. Global percentage changes are computed as the mean of the two models.

\section{Robustness and uncertainty quantification}

We adopt four strategies to investigate the uncertainty and robustness of our trend analysis results.

(i) We estimate the uncertainty for each individual observation (see Methods section 'Definition of mixed-layer depth and pycnocline stratification') and then propagate it through the linear-regression analysis (see Methods section 'Mapping method for computing climatologies and associated trends') and use it to compute the standard errors of the trends and mean fields. The standard error associated with the trends is shown in Extended Data Fig. 4. In this study, we regard trends as significant if they are larger than their estimated standard error. In all figures, insignificant trends are blanked. Standard error maps are shown in Extended Data Fig. 4.

(ii) We investigate the robustness of our linear-regression analysis by adopting two different regression models and presenting the corresponding trends (see Methods section 'Mapping method for computing climatologies and associated trends'). The impact of the regression choice is limited, and does not challenge the conclusions presented in this paper.

(iii) We investigate the potential impact of the marked variations in the global ocean-observing system that have occurred over past decades, particularly as a result of the Argo and MEOP programmes. In particular, Argo- and MEOP- based sensors are often less closely calibrated than ship-based sensors, because they are usually not recovered, so could potentially be subject to, for example, a pressure bias. In addition, pressure drift is not an issue either for Argo or for MEOP ${ }^{60,61}$. They also have coarser vertical resolution and-although this is taken into account in our standard error quantification (see (i) above)-we here seek potential systematic biases that would force a tendency (the Argo programme is the most prominent source of information after 2000). Extended Data Fig. 8 shows all mixed-layer depth estimates from closely located pairs of Argo- and ship-based profiles (sampled within $330 \mathrm{~km}$ and 1.5 days). We see differences reflecting that the mixed-layer depth anomaly can be highly variable at small scales, but we find no systematic bias that could produce an unphysical trend. Going further, by repeating the trend analysis using only ship-based profiles, most regions are blanked because observational coverage is limited, but in the few regions where coverage allows the recovery of long-term trends, the conclusions of this paper are endorsed (Extended Data Fig. 9). Limiting the analysis to only ship-based profiles strongly constrains the number of observations available, and therefore limits the spatial domain in which we are able to recover significant trends.

(iv) We compare trends in mixed-layer mean temperature to trends recovered from alternative sea surface temperature (SST) datasets. SST is arguably the best observed ocean quantity historically, with numerous in situ observations since the end of the 19th century ${ }^{62}$, enriched by the advent of global satellite remote sensing at relatively high horizontal and temporal resolutions since $1982^{63}$. The observational coverage of SST is far from perfect, even with satellite observations, which, depending on the technology used, can be blocked by cloud cover (the longest time series from as far back as 1982, and associated trends, are affected by cloud cover). However, SST remains one of the best observed variables, and is entirely independent from the observational database used in the present study. Extended Data Fig. 7 shows a map of the mixed-layer mean temperature trends from 1970 to 2018 estimated in this study, compared with other estimates derived from GHRSSTv $2^{63}$ and HaddSSTv ${ }^{62}$. The three estimates show a very consistent picture of long-term SST trends.

Although we wish to make the reader fully aware of the limitations of our analysis, each of the different approaches detailed in this section endorses our key results and provides high confidence in the conclusions of this paper.

\section{The upper ocean's vertical structure}

The 0-200 m layer cuts across several distinct dynamical regimes, depending on whether the mixed layer and pycnocline are shallower or deeper than $200 \mathrm{~m}$, which depends on the region and season (Extended Data Fig. 1).

When the mixed layer is deeper than $200 \mathrm{~m}$, the $0-200 \mathrm{~m}$ layer is contained entirely within the mixed layer, so stratification will be close to null (not exactly null, because, by definition, there is a small density difference of $0.03 \mathrm{~kg} \mathrm{~m}^{-3}$ between the ocean surface and the base of the mixed layer; see Methods section 'Definition of mixed-layer depth and pycnocline stratification'). In that context, change of the 0-200 m stratification would reflect only change in mixed-layer depth, but would be entirely unrelated to pycnocline stratification (Extended Data Fig. 1b). When the mixed layer is shallower than $200 \mathrm{~m}$, change in 0-200 m stratification is related to pycnocline stratification, but can underestimate or overestimate the actual change within the pycnocline, depending on the change in mixed-layer depth (Extended Data Fig. 1a). In this sense, annual and global mean estimates of 0-200 m stratification change amalgamate different dynamical regimes (mixed layer and pycnocline), which makes such diagnostics difficult or impossible to interpret. At the very least, these diagnostics cannot be interpreted as a measure of a strengthening of the pycnocline (which is one of the key metrics for impact and adaptation), as has been done in the past ${ }^{16}$.

In summer, most of the world ocean's mixed layers are shallower than $200 \mathrm{~m}$. In this season, the rate of change of the $0-200 \mathrm{~m}$ and pycnocline stratification can be related to the rate of change of the mixed-layer depth. With some strong assumptions, the relationship can be very easily derived analytically. For instance, assuming that all stratification change is due to surface change ${ }^{9}$ and that the $0-200$ m layer can be represented by a perfect three-layer structure with a linear density gradient in the pycnocline (Extended Data Fig. 1a), one can write:

$$
\left\{\begin{array}{c}
\overline{N_{200}^{2}} \propto \frac{\partial \sigma_{0}}{200} \\
\Delta N_{200}^{2} \propto \frac{\Delta\left(\partial \sigma_{0}\right)}{200} \\
\delta N_{200}^{2}=\frac{\Delta N_{200}^{2}}{N_{200}^{2}}=\delta\left(\partial \sigma_{0}\right)
\end{array}\right.
$$


and:

$$
\left\{\begin{array}{c}
\overline{N_{200}^{2}} \propto \frac{\partial \sigma_{0}}{h} \\
\Delta N^{2} \propto \frac{\partial \sigma_{0}+\Delta\left(\partial \sigma_{0}\right)}{h-\Delta H}-\frac{\partial \sigma_{0}}{h}=\frac{\partial \sigma_{0}}{h}\left(\frac{1+\delta\left(\partial \sigma_{0}\right)}{1-\delta H}-1\right) \\
\delta N^{2}=\frac{1+\delta\left(\partial \sigma_{0}\right)}{1-\delta H}-1=\frac{1+\delta N_{200}^{2}}{1-\delta H}-1
\end{array}\right.
$$

where the operator $\overline{(\cdot)}$ denotes a climatological mean, $\Delta$ refers to absolute change and $\delta$ refers to change relative to the climatological mean (for example, $\delta x=\Delta x /(\bar{x})$ ). We refer the reader to Extended Data Fig.1a for the meaning of $\partial \rho, \Delta(\partial \rho), h$ and $\Delta H$.

In summary, a deepening of the mixed layer sharpens the density gradient in the pycnocline, which induces an increased pycnocline density gradient much larger than that seen by the density change over a fixed depth range, even if the depth range encompasses the mixed layer and the pycnocline. Assuming an idealized vertical density profile as drawn in Extended Data Fig. 1a, an increase of $\delta N_{200}^{2}$ of 1.1-1.5\% $\mathrm{dec}^{-1}$ associated with a mixed-layer deepening of $2.2-3.6 \% \mathrm{dec}^{-1}$ would translate into an increase of $\sim 3-5 \% \mathrm{dec}^{-1}$ of $\delta N^{2}$-lower than, but consistent with, our estimate. Our goal is not to derive a detailed quantitative relationship between $\delta N^{2}, \delta N_{200}^{2}$ and $\delta H$, given that the shape of a vertical profile of density in the ocean may deviate markedly from the idealized case drawn in Extended Data Fig. 1a, which is used to derive the relationship. In particular, the pycnocline is not a linear gradient, and there are many cases in which, even in summer, the base of the pycnocline is arguably deeper than $200 \mathrm{~m}$, so that the simple relationship used here would underestimate $\delta N^{2}$.

\section{Time series of percentage anomalies}

To gain further confidence in our mapped trends, we examine time series of mixed-layer depth and pycnocline stratification in specific regions. The goal here is to visualize time series that are independent of the statistical machinery associated with the gridding procedure. As noted, this procedure will be biased owing to uneven sampling in time and space, and will tend to average out the largest changes: the local regression model procedure is more robust in this respect. We, however, produce these alternative time series primarily for visualization purposes. To minimize spatio-temporal biases linked to uneven sampling, we generate regional and yearly percentage anomaly distributions (shown as median and 33th-66th percentiles; black error bars in Figs. 3b, d, 5b, d, Extended Data Figs. 5, 6). Percentage anomaly distributions are computed from all available observations in a given region, for which we subtract from the quantity of interest its local climatological seasonal cycle and divide the anomaly by the corresponding local seasonal climatological value.

The 1970-2018 trend and associated standard error are then quantified by applying a weighted linear-regression model, which regresses the annual median values weighted by the number of observations in each year (red lines in Figs. 3b, d, 5b, d, Extended Data Figs. 5, 6; trends are only plotted if significant). A trend is considered significant if it is greater than double its estimated standard error.

\section{Winter mixed-layer and stratification trends}

Multi-decadal trends in wintertime pycnocline stratification and mixed-layer depth are shown and briefly discussed here (Extended Data Fig. 5). Consistent with summertime results, pycnocline stratification in winter undergoes a substantial strengthening (at an even greater rate than in summer), whereas the winter mixed layer is found to deepen in most regions. There are a few exceptions to this winter deepening, however, particularly in the Pacific sector of the Southern Ocean. However, as shown by Extended Data Fig. 2, the time series of winter measurements are considerably shorter than those of summer observations, and data density is much lower in winter than in summer (not shown). Caution must therefore be exerted in interpreting the mapped winter trends. Indeed, examining detailed time series from specific regions suggests that winter trends are weakly constrained (Extended Data Fig. 6). Thus, our finding of an overall, worldwide increase in winter pycnocline stratification and mixed-layer depth remains tentative and must be validated when data availability improves in the medium-term future.

\section{Dynamical forcing of changes in mixed-layer depth}

The most likely cause of the observed variations in mixed-layer depth is a change in surface-forced mechanical turbulence. Turbulence in the mixed layer can be generated by a range of processes. In this section, we explore the possibility that an intensification of some of these processes might have driven the mixed-layer deepening documented in this Article. Such an intensification is required because the mean stratification at the base of the mixed layer has increased in recent decades, implying that turbulence must have intensified to overcome the strengthening stratification and effect a mixed-layer deepening. Our analysis indicates that the mixed layer and pycnoclineaveraged stratification, $N^{2}$, has increased with time at a rate of $\sim 6 \% \mathrm{dec}^{-1}$, on the basis of the approximation $N^{2}=N_{0}^{2} / H$, where $H$ the mixed-layer depth (which has increased at a typical rate of $\sim 3 \% \mathrm{dec}^{-1}$ ) and $N_{0}^{2}$ the pycnocline stratification (which has increased at a typical rate of $\left.\sim 9 \% \mathrm{dec}^{-1}\right)$. Here we consider a range of processes that might have counteracted such increased stratification to lead to a deepening of the mixed layer.

Local one-dimensional processes generating turbulence in the mixed layer are forced at the ocean surface by air-sea buoyancy exchanges, waves and winds. Although in principle surface buoyancy forcing can drive increased surface turbulence, under the ongoing climate change, changes in buoyancy forcing act to suppress turbulence rather than promote it, as suggested by the global increase in density stratification. Surface buoyancy forcing is therefore not considered further as a driver of increased turbulence. A range of evidence indicates that injection of turbulence by breaking waves is likely to be the dominant source of turbulence near the surface ${ }^{64}$, but the contribution of wave breaking to turbulence at the mixed-layer base is less clear; modelling results suggest that it is probably a secondary effect modulating Langmuir turbulence ${ }^{65}$. Consequently, we have chosen to assess the role of the following processes that may have sizeable impacts at the mixed-layer base: (i) wave-generated Langmuir turbulence $^{66}$; (ii) wind-generated high-frequency internal waves ${ }^{38}$; and (iii) submesoscale frontal instabilities ${ }^{27}$. We stress, however, that our theoretical understanding of mixed-layer physics remains incomplete, such that it is impossible to provide a comprehensive assessment of the roles of all physical processes affecting the mixed layer. Here, we consider merely a selection of processes to demonstrate that they, individually or combined, may have potentially induced a mixed-layer deepening over recent decades in a context of increasing upper-ocean stratification.

Wave-generated Langmuir turbulence. The interaction of wave forcing with wind can drive Langmuir turbulence, which may reach the mixed-layer base ${ }^{66}$ and entrain pycnocline waters into the mixed layer. To assess the possible implication of Langmuir turbulence in mixed-layer deepening, we consider a Froude number characterizing the balance between Langmuir turbulence and stratification, given as $^{67} \mathrm{Fr}=w_{\mathrm{L}} / \mathrm{NH}$, where $w_{\mathrm{L}}$ is a characteristic Langmuir vertical velocity. This velocity can be expressed as ${ }^{37} w_{\mathrm{L}}=\left(u_{*}^{2} u_{\mathrm{S} 0}\right)$, where $u_{*}=\sqrt{\tau / \rho}$ is the water-side friction velocity, $\tau$ is the wind stress, and $u_{\mathrm{s} 0}$ is the surface Stokes drift velocity. Assuming a constant turbulent Langmuir number, $\mathrm{La}_{\mathrm{t}}=\left(u_{*} / u_{\mathrm{s} 0}\right)^{1 / 2}$, the Langmuir vertical velocity scales as $w_{\mathrm{L}} \propto u_{*} . \mathrm{Nu}-$ merical experiments have shown that Langmuir-driven vertical mixing is limited once a constant Froude number is reached ${ }^{67}$, meaning that 
the mixed-layer depth controlled by Langmuir turbulence scales as:

$$
H \propto \frac{u_{*}}{N}
$$

This relation can also be derived using a Richardson number scaling based on direct surface forcing from winds and waves.

From dimensional arguments, wind stress is frequently parameterized as $\tau=C_{\mathrm{D}} \rho U_{10}^{2}$, where $U_{10}$ is the $10-\mathrm{m}$ wind speed. However, the non-dimensional drag coefficient, $C_{\mathrm{D}}$, varies with $U_{10}$ owing to changes in sea surface roughness with wind speed. The global average of observations of this dependency is linear within statistical uncertainty over the approximate range $5 \mathrm{~m} \mathrm{~s}^{-1}<U_{10}<20 \mathrm{~m} \mathrm{~s}^{-1}$ (ref. ${ }^{68}$ ). Because the vast majority of the wind data exhibiting increasing trends of $U_{10}$ falls within this range ${ }^{10}$, the scaling of wind stress with wind speed can be represented as $\tau \propto U_{10}^{3}$, leading to $u_{*} \propto U_{10}^{3 / 2}$ for the following analysis.

We now introduce $\delta$, the percentage change in any given quantity $x$, so that $\delta x=\Delta x / \bar{x}$, with $\Delta x$ referring to absolute change and $\bar{x}$ to a climatological mean value. Applying this scaling to equation (9) gives $H \propto U_{10}^{3 / 2} / N$, which we can then translate into an estimate of the percentage change in mixed-layer depth expected from variations in Langmuir forcing, namely, $\bar{H}+\Delta H \propto\left(\bar{U}_{10}+\Delta U_{10}\right)^{3 / 2} /(\bar{N}+\Delta N)$. This can be rewritten as $\bar{H}(1+\delta H) \propto\left(\bar{U}_{10}^{3 / 2} / \bar{N}\right)\left(1+\delta U_{10}\right)^{3 / 2} /(1+\delta N)$ and simplified to $(1+\delta H) \propto\left(1+\delta U_{10}\right)^{3 / 2} /(1+\delta N)$.

Ship-and satellite-based records ${ }^{10,11,69}$ suggest that mean open-ocean wind speeds have intensified by approximately $\delta U_{10} \approx 1-3 \% \mathrm{dec}^{-1}$ in recent decades (this is also endorsed by a wide range of atmospheric reanalyses $\left.{ }^{39}\right)$; as discussed above, $\delta N \approx 2.5 \% \operatorname{dec}^{-1}\left(\delta N^{2} \approx 6 \% \mathrm{dec}^{-1}\right)$. Applying the preceding scaling to these values suggests that Langmuir turbulence may have effected a deepening of the mixed layer at a rate of $0-2 \% \mathrm{dec}^{-1}$, considerably lower than, but of consistent order of magnitude with, the observed mixed-layer deepening, $\delta H \approx 3 \% \mathrm{dec}^{-1}$. Because mixed-layer deepening typically occurs during strong forcing events, trends in these strong events may be more relevant than trends in mean conditions. Multi-decadal increases in 90th-percentile wind speeds have more than doubled those of the seasonal-or annual-mean wind speeds ${ }^{10,11}$. This suggests that an intensification of wind and wave forcing may be a plausible explanation for our observed mixed-layer deepening. However, there are considerable measurement and sampling uncertainties associated with both in situ and satellite observations of intermittent, strong wind forcing events, which make a more quantitative assessment difficult.

Wind-generated high-frequency internal waves. High-frequency wind forcing generates an internal-wave field at the base of the mixed layer, which can then trigger a forward energy cascade to dissipation ${ }^{38}$. In an idealized, high-resolution numerical experiment, Barkan et al. ${ }^{38}$ demonstrated the importance of the internal-wave-mediated forward cascade by showing that the ratio between the enhanced dissipation rate and the added high-frequency wind work is 1.3 when turning on high-frequency winds. Past observations show a marked increase of high-frequency winds over recent decades that is surprisingly consistent on a global scale, although possibly larger in the Southern Hemisphere (similar to our estimated mixed-layer deepening), occurring at a rate ${ }^{10,11}$ of $2 \% \mathrm{dec}^{-1}$. If we assumed that the surface ocean velocity field has not changed substantially in recent decades, we would infer an increase in the wind work associated with high-frequency winds of similar magnitude to that in the wind stress, which (see above) scales like $\tau \propto U_{10}^{3}$. The wind work associated with high-frequency winds would therefore have increased at a rate of $\sim 6 \% \mathrm{dec}^{-1}$. Using the relationship of Barkan et al., we infer an enhancement in the dissipation driven by internal waves generated by intensifying high-frequency winds at a rate $30 \%$ greater than that of the associated wind work increase. This translates into a dissipation rate enhancement of the order of $\sim 40 \% \mathrm{dec}^{-1}$.
This is a large increase in dissipation, which we attempt to relate to an expanding mixing depth through the Ozmidov length scale, which characterizes turbulent mixing in stratified waters $\mathrm{s}^{70,71}$ :

$$
L_{\mathrm{O}}=\varepsilon^{1 / 2} N^{-3 / 2} \text {. }
$$

On the basis of this relationship, a $\sim 40 \% \mathrm{dec}^{-1}$ increase in $\varepsilon$, concomitant with a $2.5 \% \mathrm{dec}^{-1}$ increase in $N$, would result in a deepening mixed layer of the order of $14 \% \mathrm{dec}^{-1}$, five times larger than our global mixed-layer deepening (occurring at a rate of $\sim 3 \% \mathrm{dec}^{-1}$ ). Although this scaling argument is contingent on many arbitrary approximations, it highlights a potentially efficient process to deepen the mixed layer in a stratifying ocean.

Submesoscale frontal instabilities. There is a vast diversity of processes that can occur at submesoscales in the upper ocean, and that may deepen or shoal the mixed layer. Many studies have shown how processes linked to submesoscale frontogenesis may drive upward buoyancy fluxes that act to restratify the mixed layer ${ }^{40,41,72,73}$. However, other submesoscale frontal processes (notably, symmetric instability) energize upper-ocean turbulence. Although the large-scale effects of symmetric instabilities in the ocean remain poorly constrained, we here quantify the change in turbulent dissipation associated with symmetric instabilities, $\varepsilon_{\mathrm{SI}}$, that might have occurred in recent decades. Near the mixed-layer base (for example, at depths exceeding $(3 / 4) H$ ), $\varepsilon_{\mathrm{SI}}$ may be quantified as ${ }^{27}$ :

$$
\varepsilon_{\mathrm{SI}}=\left(\begin{array}{ll}
\frac{1}{4} B_{\mathrm{e}} & \text { if } B_{\mathrm{e}}>0 \\
0 & \text { otherwise, }
\end{array}\right.
$$

where $B_{\mathrm{e}}$ is the wind-driven Ekman buoyancy flux. When the wind stress is directed 'down' on an upper-ocean front (that is, an area of enhanced horizontal density contrast), the Ekman flow conveys waters from the dense side to the light side of the front (by 'wind directed down front' we mean wind oriented along and in the same direction as the oceanic frontal jet). This triggers symmetric instability, which grows by extracting energy from the front's vertical shear ${ }^{74-76}$. The Ekman buoyancy flux is given by $B_{\mathrm{e}}=\frac{\tau f}{\rho f^{2}} \nabla_{\mathrm{h}} b$, where $\nabla_{\mathrm{h}} b$ is the submesoscale horizontal buoyancy gradient on which a wind stress, $\tau$, acts. At any location in the ocean, there is a probability, $P$, of the wind stress being partially or fully directed down a submesoscale front, resulting in $B_{\mathrm{e}}>0$. The rate of turbulent kinetic energy dissipation associated with wind-forced symmetric instability is then $\varepsilon_{\mathrm{SI}}=\frac{P}{4} B_{\mathrm{e}} \propto \tau \nabla_{\mathrm{h}} b$. We now assume that changes in the square of the submesoscale horizontal buoyancy gradient in the mixed layer are related to those in $N_{0}^{2}$, the stratification in the pycnocline, through the three-dimensional frontogenetic distortion of the vertical density gradient by mesoscale motions ${ }^{77}$. We thus have: $\left(\nabla_{\mathrm{h}} b\right)^{2} \propto N_{0}^{2}$ and $\tau \propto U_{10}^{3}$ (see above), which we use to translate $\varepsilon_{\mathrm{SI}} \propto \tau \nabla_{\mathrm{h}} b$ into $\varepsilon_{\mathrm{SI}} \propto U_{10}^{3} N_{0}$. Finally, it follows that the scaling for a change in $\varepsilon_{\mathrm{SI}}$ is $\delta \varepsilon_{\mathrm{SI}} \propto\left(1+\delta U_{10}\right)^{3}\left(1+\delta N_{0}\right)-1$, which implies a change in mixing length scale of (see equation (10)):

$$
1+\delta L_{\mathrm{O}} \propto\left(\frac{1+\delta U_{10}}{1+\delta N}\right)^{3 / 2} \sqrt{1+\delta N_{0}} .
$$

Using our best estimates of the characteristic percentage changes in the three parameters on the right-hand side $\left(\delta U_{10} \approx 1-3 \% \mathrm{dec}^{-1}\right.$, $\delta N_{0} \approx 9 \% \mathrm{dec}^{-1}, \delta N \approx 2.5 \% \mathrm{dec}^{-1}$ ), equation (12) suggests an increase in the mixing length scale of $\sim 3 \% \mathrm{dec}^{-1}$, in broad agreement with our observations of mixed-layer deepening of $\sim 3 \% \mathrm{dec}^{-1}$.

\section{Summary}

Although these scaling arguments are associated with multiple approximations and uncertainties, they do suggest that intensifying winds 
(and, in the symmetric instability case, the enhanced pycnocline stratification itself) provide a plausible driver of our observed multi-decadal deepening of the mixed layers across the world ocean, concomitant with increased pycnocline stratification. Among the three mechanisms connecting winds to invigorated turbulent mixing explored here, the intensification of wind-driven high-frequency internal-wave turbulence appears to provide the most plausible process for two reasons: first, because of the observed world-wide, consistent strengthening of high-frequency winds, consistent with our observed mixed-layer deepening; and second, because scaling arguments suggest that it could be highly efficient at expanding the mixing depth. By contrast, while the submesoscale symmetric instability may also have had a role, it remains unclear what the net effect of energized submesoscales would be on mixed-layer depth, given the restratifying action of submesoscale frontogenetic processes. Finally, wave-driven Langmuir turbulence may also have been a driver of mixed-layer deepening, but our scaling arguments suggest a weaker effect. We conclude that although these scaling analyses are merely illustrative, they suggest that a global intensification of winds may have forced a deepening of the mixed layer in the presence of increasing stratification over recent decades, and that a range of oceanic processes may have been involved. The intensification of winds in recent decades is indicated by both ship- and satellite-based records ${ }^{10,11,69}$, as well as by reanalysis products $^{39}$. Assessing this proposition and clarifying the key mixed-layer deepening mechanisms is a pressing challenge that must be addressed by follow-up investigations.

\section{Data availability}

All information about the source database used in the paper is available at https:/github.com/jbsallee-ocean/GlobalMLDchange/tree/main/ Databases. The resulting global maps of trends and climatological fields presented here are available at https://zenodo.org/record/4073174\#. YA_jsC2S3XQ (https://doi.org/10.5281/zenodo.4073174.

\section{Code availability}

The code used to generate the analysis presented in the paper and its Supplementary Information is available at https://github.com/ jbsallee-ocean/GlobalMLDchange.

45. Durack, P. J., Wijffels, S. E. \& Boyer, T. P. in Ocean Circulation and Climate Vol. 103 (eds. Siedler, G. et al.) Ch. 28, 727-757 (Academic Press, 2013).

46. Mantyla, A. W. The treatment of inconsistencies in Atlantic deep water salinity data. Deep Sea Res. Part I 41, 1387-1405 (1994).

47. Sloyan, B. M. et al. The global ocean ship-based hydrographic investigations program (GO-SHIP): a platform for integrated multidisciplinary ocean science. Front. Mar. Sci. 6, 445 (2019).

48. Riser, S. C. et al. Fifteen years of ocean observations with the global Argo array. Nat. Clim. Chang. 6, 145-153 (2016).

49. Roemmich, D. et al. On the future of argo: a global, full-depth, multi-disciplinary array. Front. Mar. Sci. 6, 439 (2019).

50. Roquet, F. et al. A Southern Indian Ocean database of hydrographic profiles obtained with instrumented elephant seals. Sci. Data 1, 140028 (2014).

51. Durack, P. J., Gleckler, P. J., Landerer, F. W. \& Taylor, K. E. Quantifying underestimates of long-term upper-ocean warming. Nat. Clim. Chang. 4, 999-1005 (2014).

52. Brainerd, K. E. \& Gregg, M. C. Surface mixed and mixing layer depths. Deep Sea Res. Part I 42, 1521-1543 (1995).

53. Thomson, R. E. \& Fine, I. V. Estimating mixed layer depth from oceanic profile data. J. Atmos. Ocean. Technol. 20, 319-329 (2003).

54. Holte, J. \& Talley, L. A new algorithm for finding mixed layer depths with applications to Argo data and subantarctic mode water formation. J. Atmos. Ocean. Technol. 26, 1920-1939 (2009).
55. Sallée, J. B., Wienders, N., Speer, K. \& Morrow, R. Formation of subantarctic mode water in the southeastern Indian Ocean. Ocean Dyn. 56, 525-542 (2006).

56. Pedlosky, J. Geophysical Fluid Dynamics (Springer, 1987).

57. Jakobsen, P. K., Ribergaard, M. H., Quadfasel, D., Schmith, T. \& Hughes, C. W. Near-surface circulation in the northern North Atlantic as inferred from Lagrangian drifters: variability from the mesoscale to interannual. J. Geophys. Res. Oceans 108, 3251 (2003).

58. Lacasce, J. H. Floats and f/H. J. Mar. Res. 58, 61-95 (2000).

59. Dijkstra, E. W. et al. A note on two problems in connexion with graphs. Numer. Math. 1 269-271 (1959).

60. Roquet, F. et al. Delayed-mode calibration of hydrographic data obtained from animal-borne satellite relay data loggers. J. Atmos. Ocean. Technol. 28, 787-801 (2011).

61. Boehme, L. et al. Animal-borne CTD-satellite relay data loggers for real-time oceanographic data collection. Ocean Sci. 5, 685-695 (2009).

62. Kennedy, J., Rayner, N., Atkinson, C. \& Killick, R. An ensemble data set of sea surface temperature change from 1850: the Met Office Hadley Centre HadSST. 4.0. 0.0 data set. J. Geophys. Res. Atmos. 124, 7719-7763 (2019).

63. Banzon, V., Smith, T. M., Chin, T. M., Liu, C. \& Hankins, W. A long-term record of blended satellite and in situ sea-surface temperature for climate monitoring, modeling and environmental studies. Earth Syst. Sci. Data 8, 165-176 (2016).

64. Sutherland, P. \& Melville, W. K. Field measurements of surface and near-surface turbulence in the presence of breaking waves. J. Phys. Oceanogr. 45, 943-965 (2015).

65. Sullivan, P. P., McWilliams, J. C. \& Melville, W. K. Surface gravity wave effects in the oceanic boundary layer: large-eddy simulation with vortex force and stochastic breakers. J. Fluid Mech. 593, 405-452 (2007).

66. Li, M., Zahariev, K. \& Garrett, C. Role of Langmuir circulation in the deepening of the ocean surface mixed layer. Science 270, 1955-1957 (1995).

67. Li, M. \& Garrett, C. Mixed layer deepening due to Langmuir circulation. J. Phys. Oceanogr. 27, 121-132 (1997).

68. Edson, J. B. et al. On the exchange of momentum over the open ocean. J. Phys. Oceanogr. 43, 1589-1610 (2013).

69. Tokinaga, H. \& Xie, S.-P. Wave- and anemometer-based sea surface wind (waswind) for climate change analysis. J. Clim. 24, 267-285 (2011).

70. Ozmidov, R. On the turbulent exchange in a stably stratified ocean. Atmos. Oceanic Phys. 1, 493-497 (1965).

71. Riley, J. J. \& Lelong, M.-P. Fluid motions in the presence of strong stable stratification. Annu. Rev. Fluid Mech. 32, 613-657 (2000).

72. Klein, P. \& Lapeyre, G. The oceanic vertical pump induced by mesoscale and submesoscale turbulence. Annu. Rev. Mar. Sci. 1, 351-375 (2009).

73. Lapeyre, G., Klein, P. \& Hua, B. L. Oceanic restratification forced by surface frontogenesis. J. Phys. Oceanogr. 36, 1577-1590 (2006).

74. Thomas, L. N. Destruction of potential vorticity by winds. J. Phys. Oceanogr. 35, 24572466 (2005).

75. Thomas, L. N. \& Lee, C. M. Intensification of ocean fronts by down-front winds. J. Phys. Oceanogr. 35, 1086-1102 (2005).

76. D'Asaro, E., Lee, C., Rainville, L., Harcourt, R. \& Thomas, L. Enhanced turbulence and energy dissipation at ocean fronts. Science 332, 318-322 (2011).

77. Tandon, A. \& Garrett, C. Mixed layer restratification due to a horizontal density gradient. J. Phys. Oceanogr. 24, 1419-1424 (1994).

Acknowledgements This project received funding from the European Union's Horizon 2020 Research and Innovation programme under grant agreement number 821001 . V.P., C.A., E.P. and L.V. received funding from the European Research Council (ERC) under the European Union's Horizon 2020 Research and Innovation programme (grant agreement 637770). A.N.G. acknowledges the support of the Royal Society and the Wolfson Foundation. P.S. received funding from the European Research Council (ERC) under the European Union's Horizon 2020 Research and Innovation programme (grant agreement No 805186). We thank I. Young for providing the percentage rate change of $10-\mathrm{m}$ wind speed from recently published analysis. We thank L. Sigelman and G. Madec for comments and discussions that greatly helped us to refine our study.

Author contributions J.-B.S. designed the experiment and performed the computations and data analyses; V.P., C.A., E.P. and L.V. helped with the development of the global database and its analysis, and evaluated the analysis; S.S. developed the mapping method; and A.N.G. and P.S. provided expertise on surface ocean turbulence and associated scaling arguments. M.K. provided expertise on the statistical methods used in this study. All authors discussed the results and wrote the manuscript.

Competing interests The authors declare no competing interests.

Additional information

Supplementary information The online version contains supplementary material available at https://doi.org/10.1038/s41586-021-03303-x.

Correspondence and requests for materials should be addressed to J.-B.S.

Peer review information Nature thanks Paul Durack, Stephen Riser and the other, anonymous, reviewer(s) for their contribution to the peer review of this work.

Reprints and permissions information is available at http://www.nature.com/reprints. 


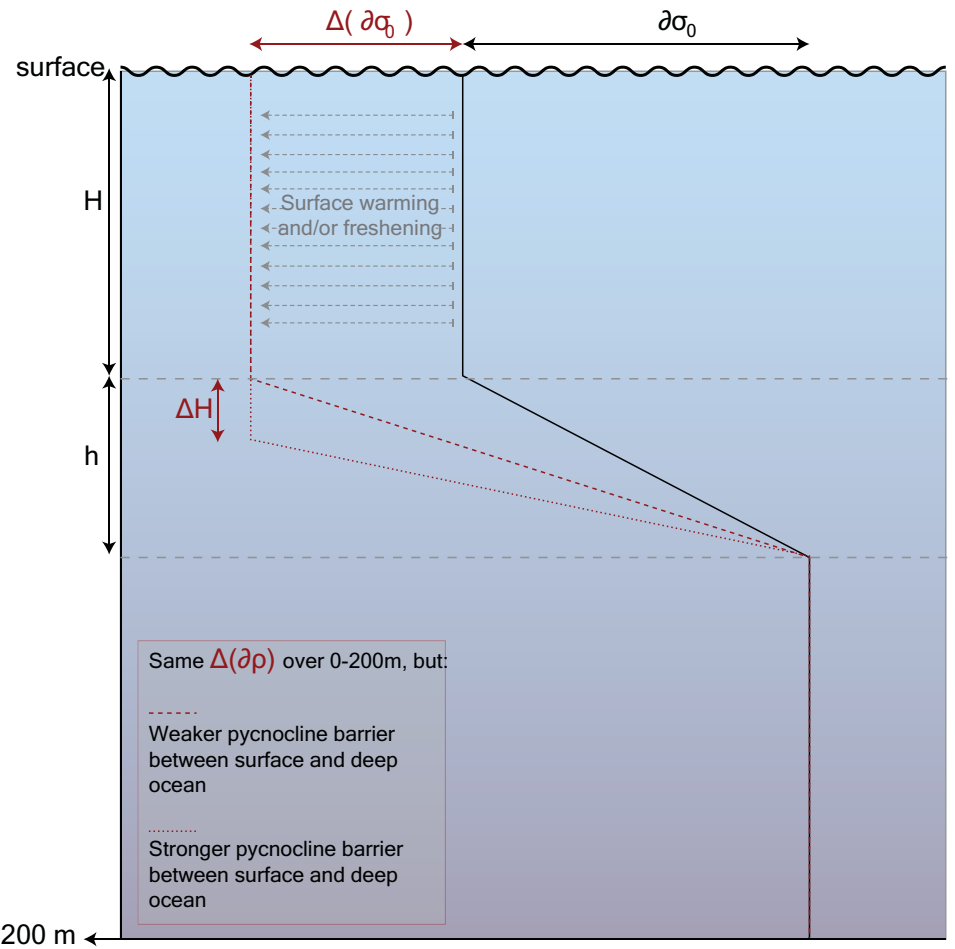

b

Case 2: Mixed-layer deeper than $200 \mathrm{~m}$

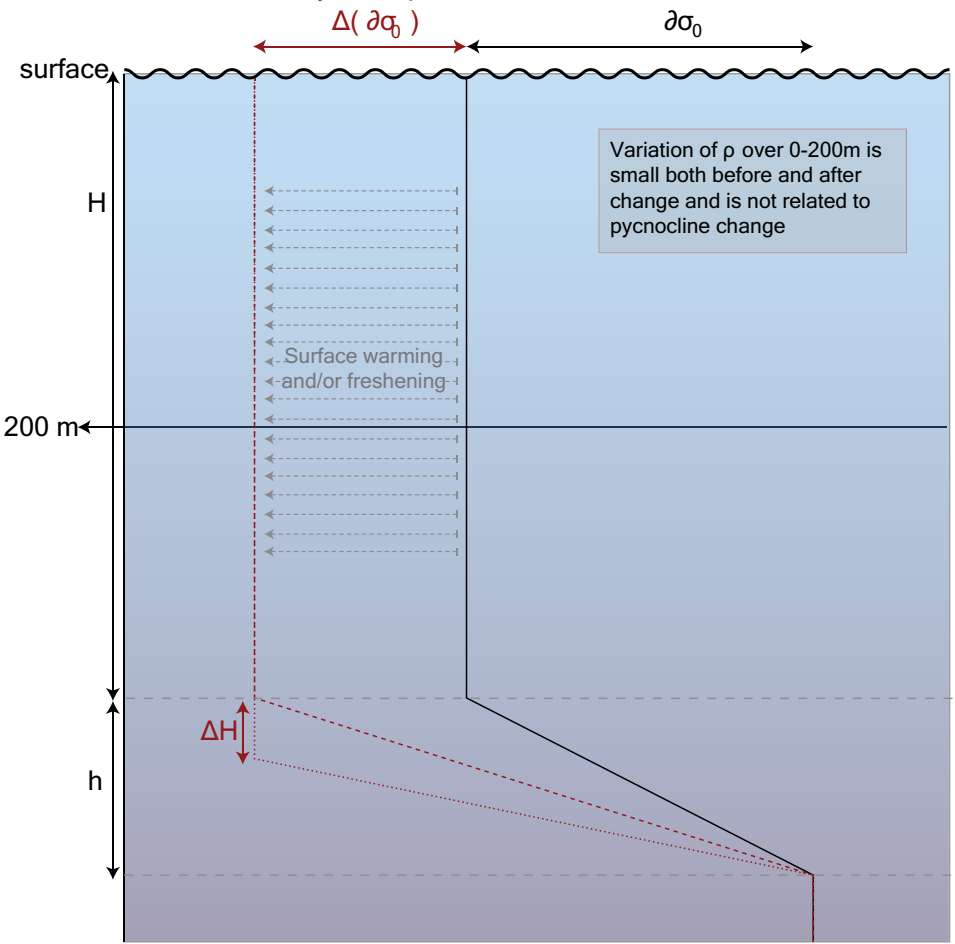

Extended Data Fig. $1 \mid$ Trends associated with the vertical structure of the upper ocean. a, b, Schematics showing idealized density profiles in the upper ocean for the cases in which the mixed layer and pycnocline are shallower (a) and deeper (b) than $200 \mathrm{~m}$. The black line shows the typical shape of the density profile with a total density increase of $\partial \rho$ across the pycnocline (thickness $h$ ) and the mixed layer (thickness $H$ ). The dashed red lines show the density profiles after lightening of the mixed layer with no change of mixed-layer depth, and the dotted red lines show the density profiles after lightening of the mixed layer concomitant with a deepening of the mixed layer. 


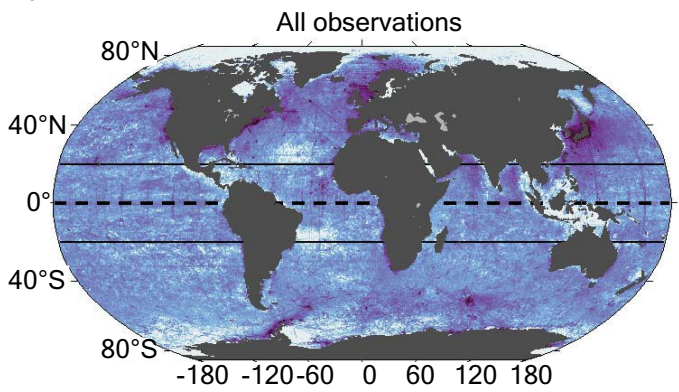

c

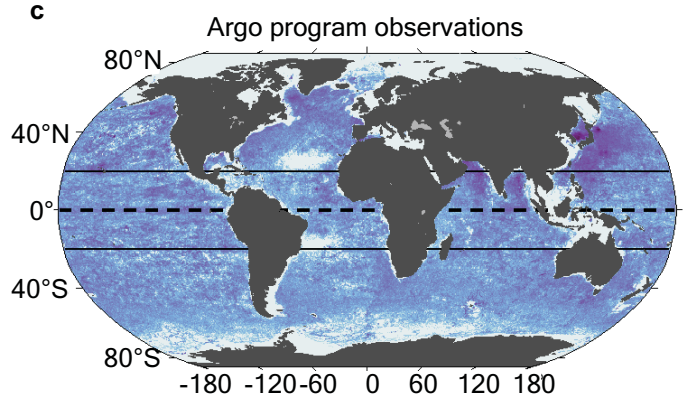

e $\quad$ Maximum time difference in summer

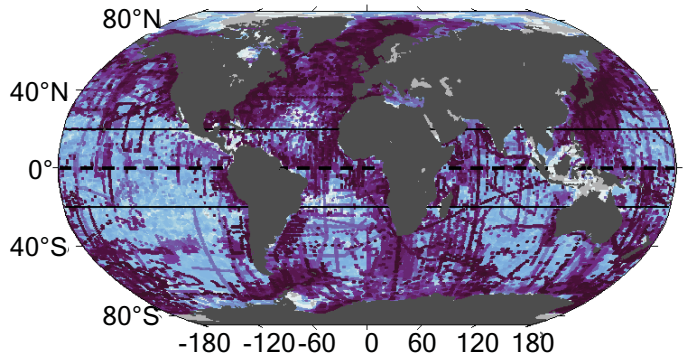

b

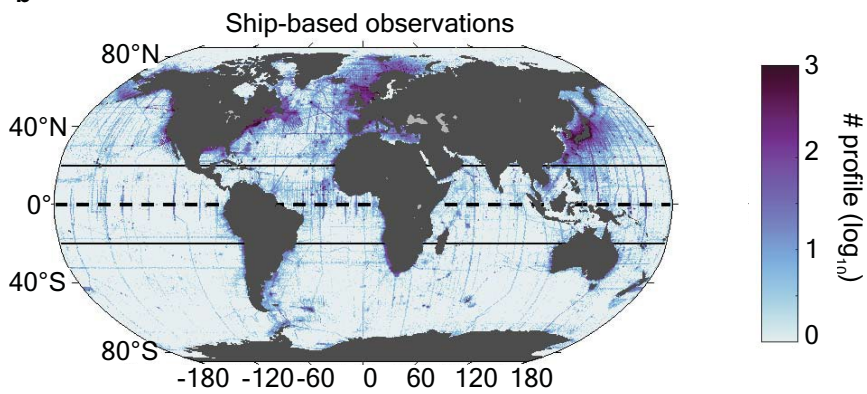

d $\quad$ MEOP program (marine mammals) observations

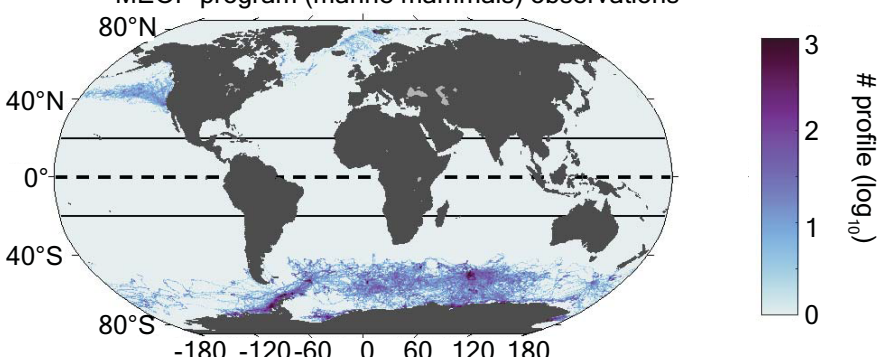

f Maximum time difference in winter

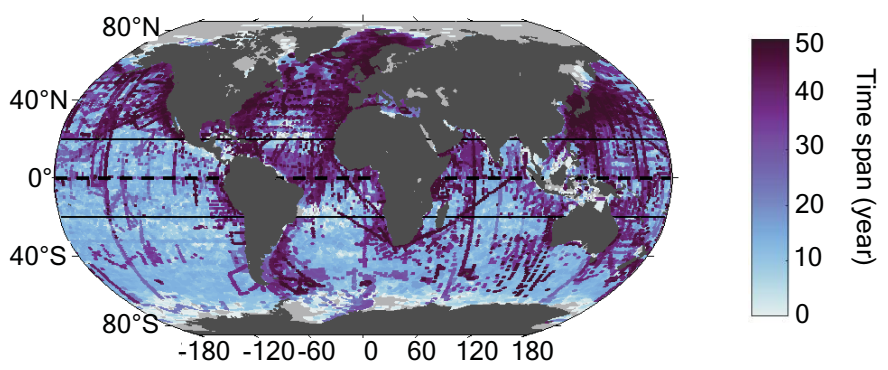

Extended Data Fig. 2 | Geographical distribution of available observations. a-d, Number of mixed layer estimates in $1^{\circ} \times 1^{\circ}$ longitude-latitude bins: from all available observation sources (a), from ship profiles (b), from Argo profiles (c) and from instrumented marine mammal observations (d).e,f, Maximum time span (in years) covered by the combined dataset in $1^{\circ} \times 1^{\circ}$ longitude-latitude bins in summer (e) and in winter (f). 
Winter mixed layer depth $(\mathrm{m})$

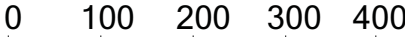

a

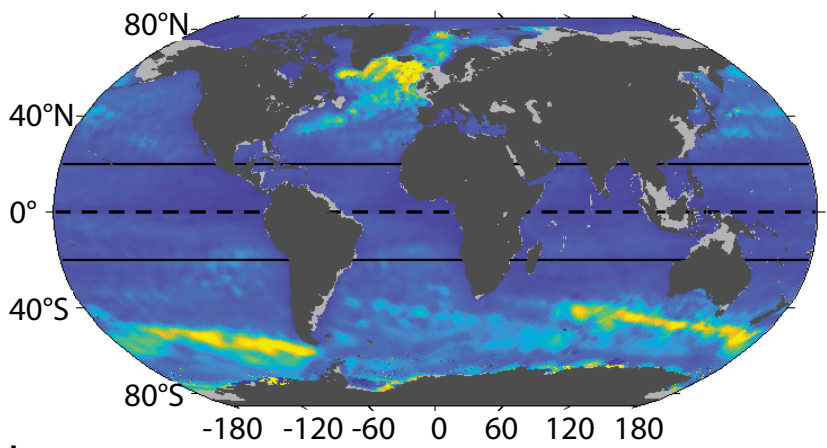

b

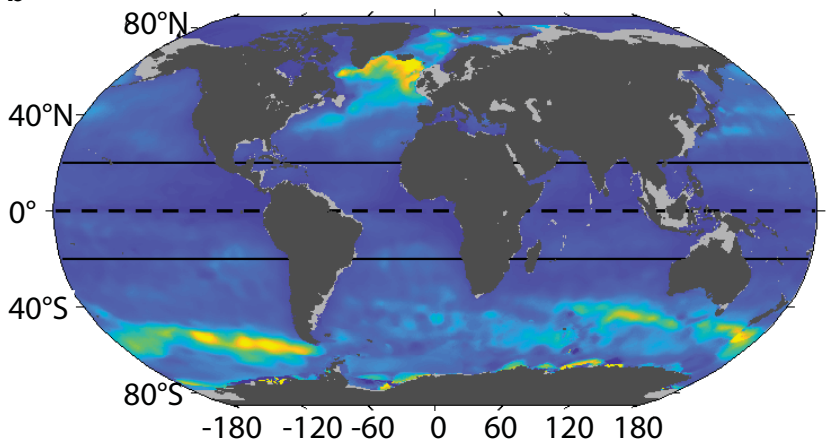

Extended Data Fig. 3 | Impact of linear-regression choices on mean mixed layer. a-d, Winter $(\mathbf{a}, \mathbf{b})$ and summer $(\mathbf{c}, \mathbf{d})$ mean mixed-layer depth computed using slightly different linear-regression models: Choice 1 (a, c; covariance
Summer mixed layer depth $(\mathrm{m})$

0

50 100

c

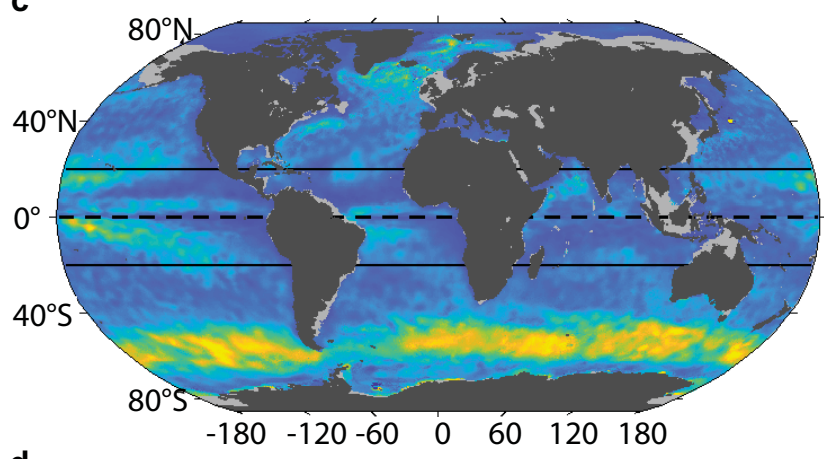

d

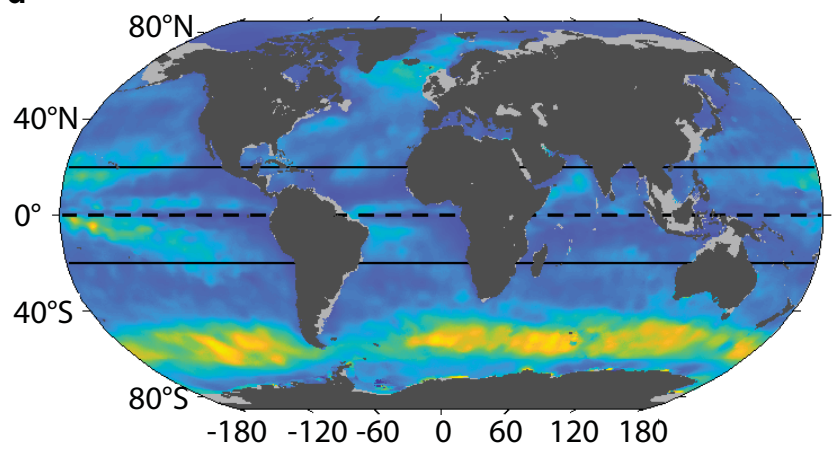

between observations) and Choice 2 (b, d; no covariance between observations). See Methods for more details. 
Summer mixed-layer depth trend $(\mathrm{m} / \mathrm{dec})$

a
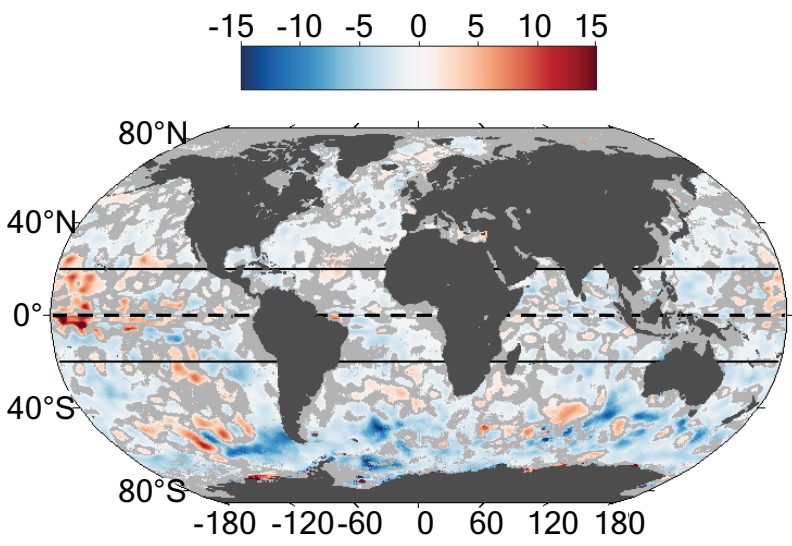

C

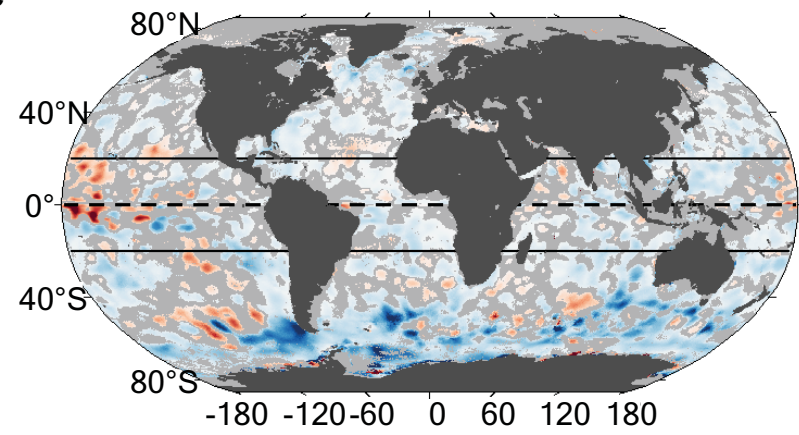

Summer stratification trend $\left(\mathrm{N}^{2} / \mathrm{dec} ; \mathrm{s}^{-2} / \mathrm{dec}\right)$

e $-10^{-4}-10^{-5}-10^{-6} 010^{-6} 10^{-5} 10^{-4}$

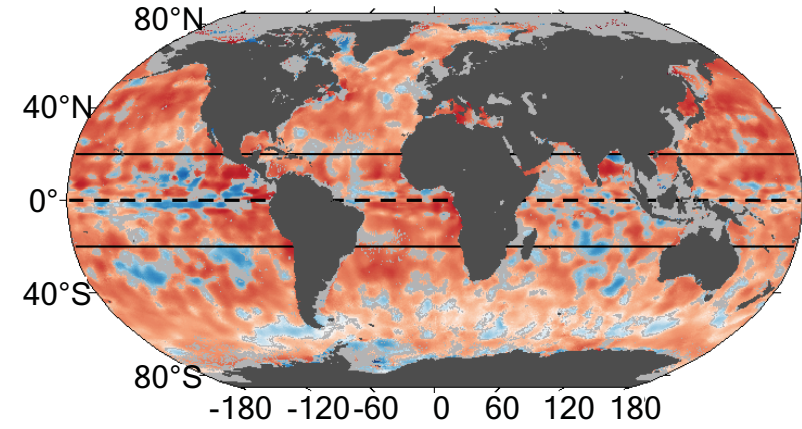

g

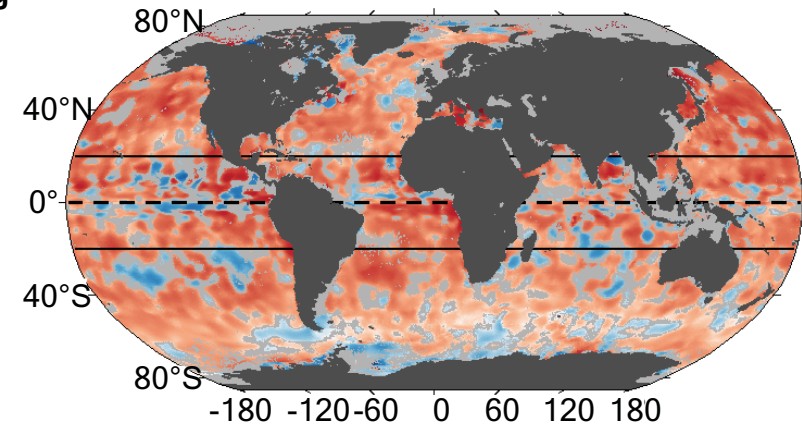

Extended Data Fig. 4 | Impact of linear-regression choices on summer mixed-layer depth, stratification trends and their associated standard errors. a-h, 1970-2018 summer trend for mixed-layer depth (a, c) and summer pycnocline stratification $(\mathbf{e}, \mathbf{g})$ and their associated standard error: standard error of mixed-layer depth trend $(\mathbf{b}, \mathbf{d})$ and standard error of summer
Error of summer mixed-layer depth trend $(\mathrm{m} / \mathrm{dec})$

b

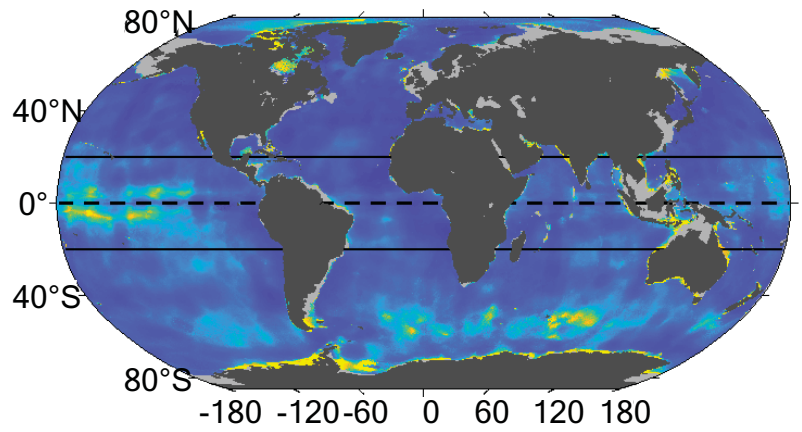

d

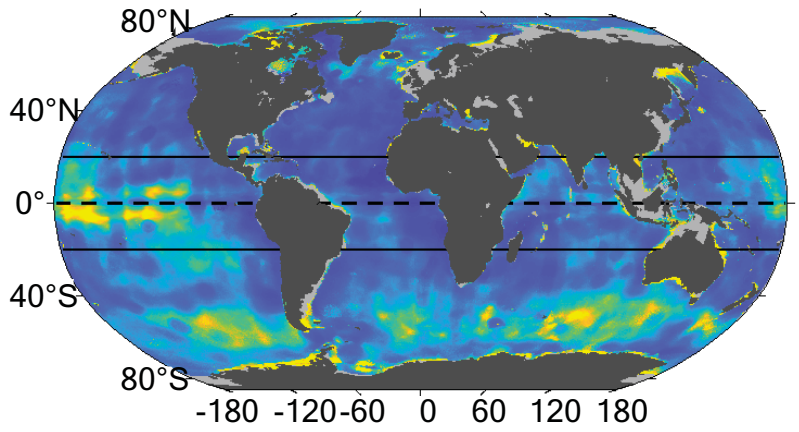

Error of summer stratification trend $\left(\mathrm{N}^{2} / \mathrm{dec} ; \mathrm{s}^{-2} / \mathrm{dec}\right)$

f

$10^{-7} \quad 10^{-6} \quad 10^{-5}$

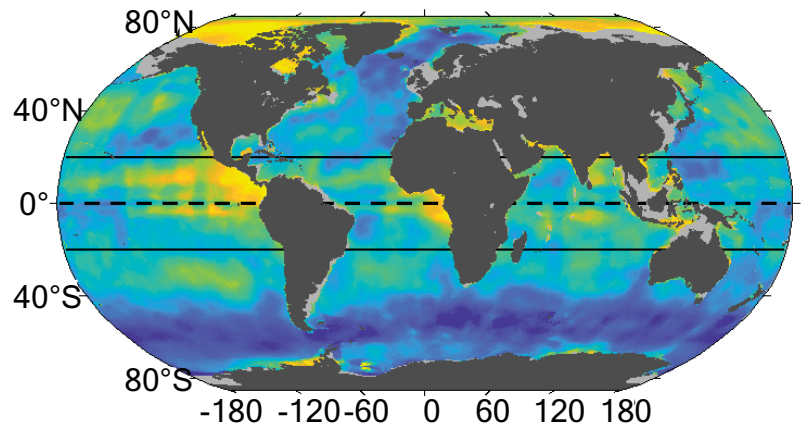

h

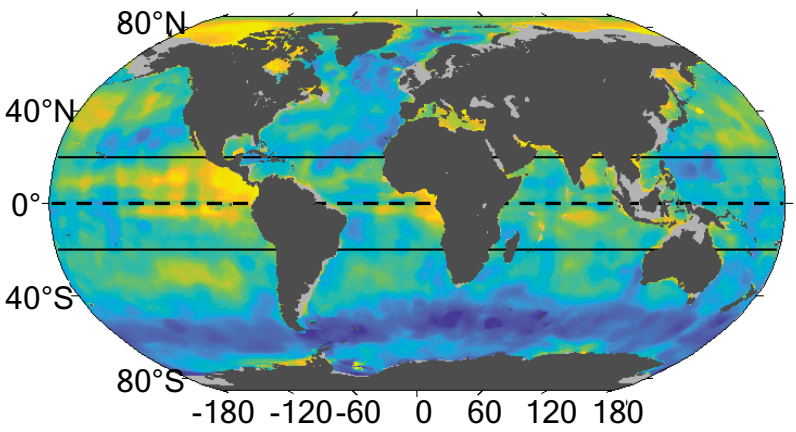

pycnocline stratification trend $(\mathbf{f}, \mathbf{h}) . \mathbf{a}, \mathbf{b}, \mathbf{e}, \mathbf{f}$ show the solution computed with the linear-regression model Choice 1 (covariance between observations); $\mathbf{c}, \mathbf{d}, \mathbf{g}, \mathbf{h}$ show the solution computed with the linear-regression model Choice 2 (no covariance between observations). 
a

Winter 0-200 m stratification trend: $\mathrm{N}^{2}{ }_{200}$ trend $\left(\mathrm{s}^{-2} / \mathrm{dec}\right)$
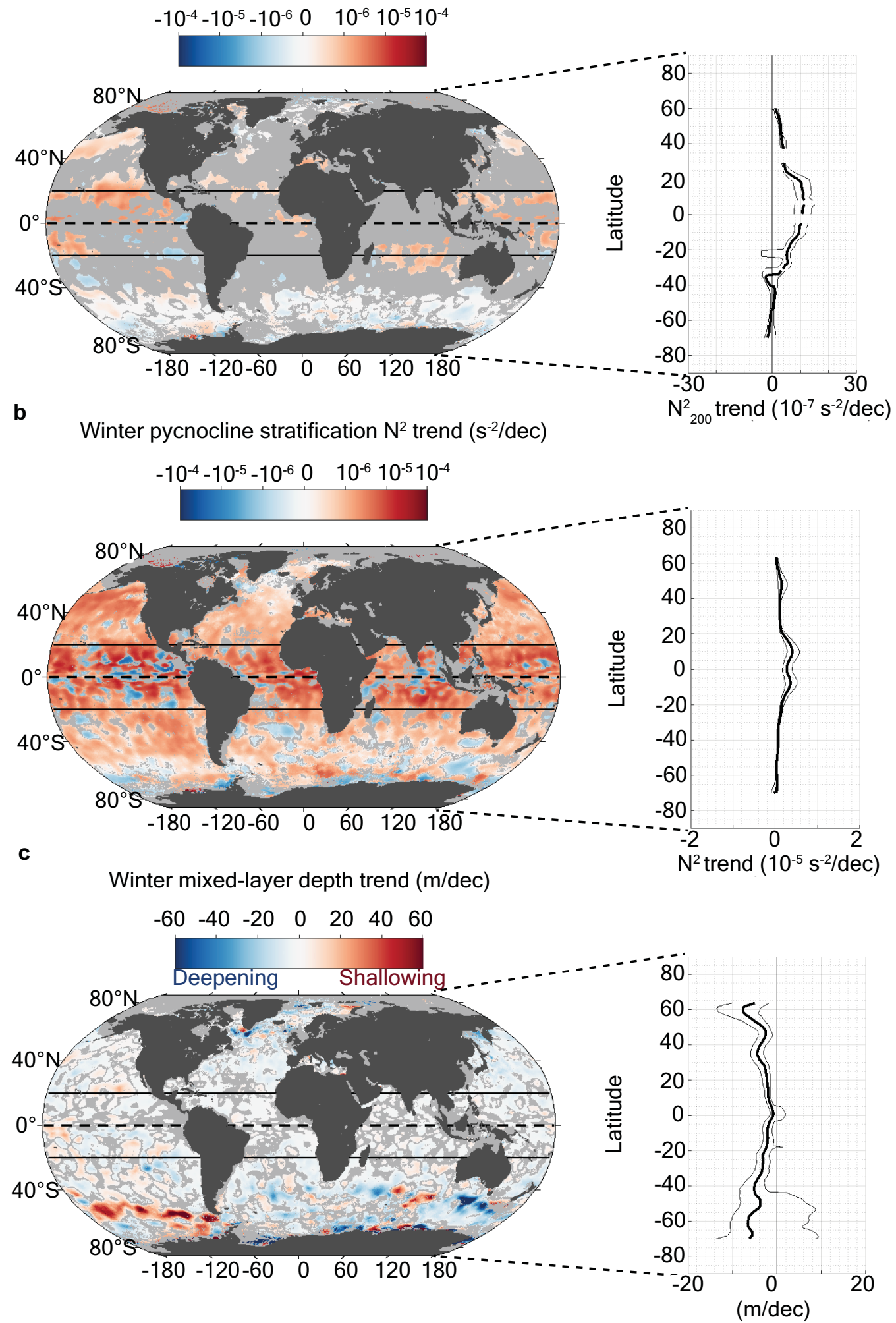

Extended Data Fig. 5 | 1970-2018 trends in winter upper-ocean stratification and mixed-layer depth. a, b, Map of the 1970-2018 winter $0-200 \mathrm{~m}$ trend $\left(\mathbf{a} ; N_{200}^{2}\right.$ trend in s$\left.~^{-2} \mathrm{dec}^{-1}\right)$ and pycnocline stratification trend $(\mathbf{b}$; $N^{2}$ trend in s${ }^{-2} \mathrm{dec}^{-1}$ ); thick black lines show the zonal-median value and thin black lines show the 33th-66th percentile. Regions with no significant trend (see Methods) are shaded in grey on the map. c, As in a, b, but for winter mixed-layer trend, in $\mathrm{m} \mathrm{dec}^{-1}$ (mixed-layer deepening is shown as a negative trend). 


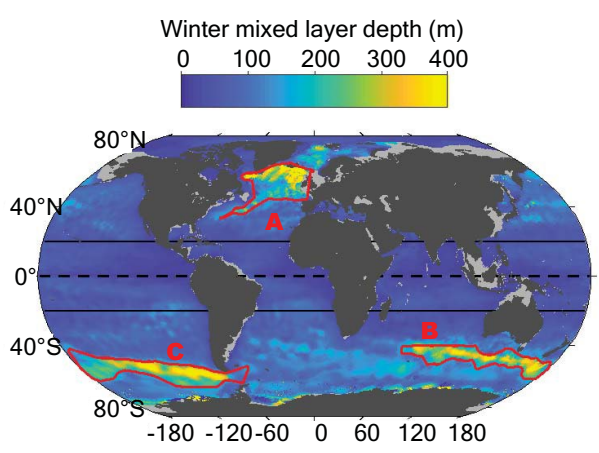

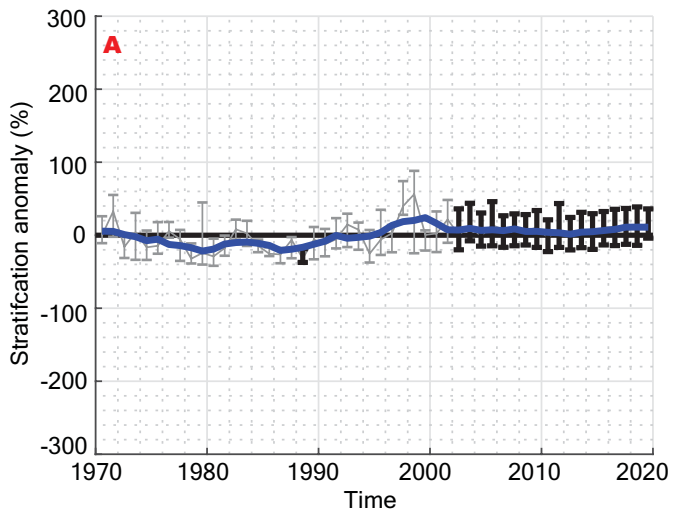
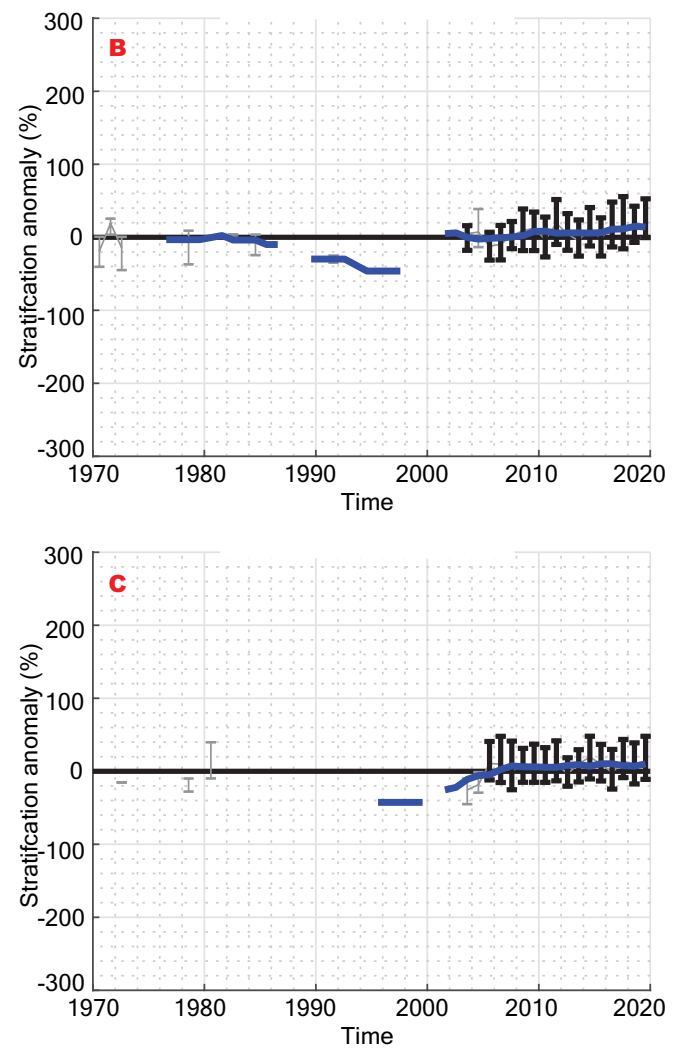

Extended Data Fig. 6 | Regional time series of winter pycnocline stratification and mixed-layer depth anomaly.a, Winter climatological mixed-layer depth (same as Fig. $2 \mathrm{f}$ ) with three specific regions of interest outlined by red contours: North Atlantic subpolar convection region (A); Southern Ocean Indian sector convection region (B); and Southern Ocean Pacific sector convection region (C). b, d, f, Winter stratification anomaly time series and associated trends for regions $\mathrm{A}(\mathbf{b}), \mathrm{B}(\mathbf{d})$ and C (f).c, e, g, Winter mixed-layer depth anomaly times series and associated trends for regions $A(\mathbf{c})$,
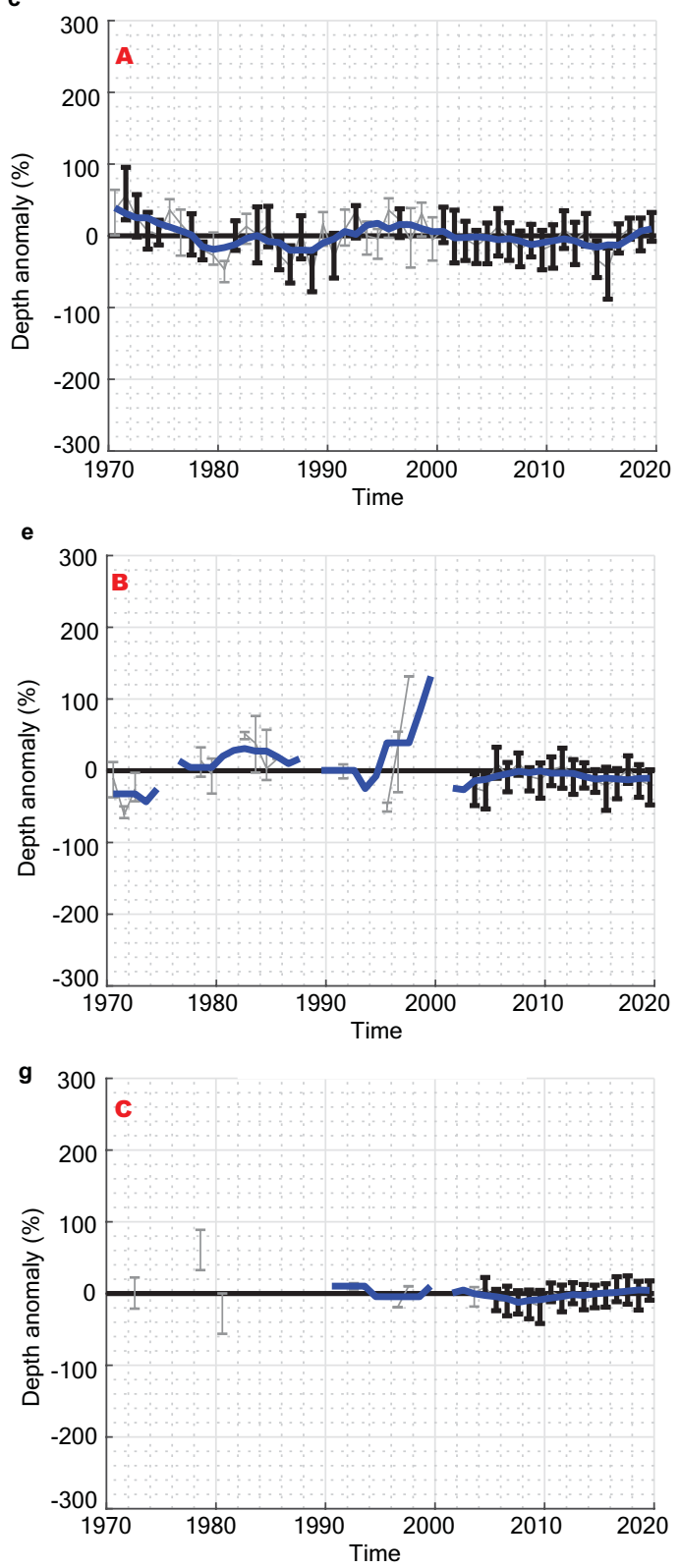

B (e) and C (g). A negative depth anomaly refers to a deepening. Each time series shows: thin grey line, the annual median percentage anomaly (from the local climatological seasonal cycle), computed for each individual observation; error bars referring to the 33th-66th percentile range of the percentage anomaly (error bars are shown in black (grey) when more (fewer) than 50 data points are used in the annual statistics); the associated five-year smoothed median time series superimposed in blue; and a linear trend from 1970-2018, shown by the red line, if greater than twice its standard error. 
This study

(1970-2018)

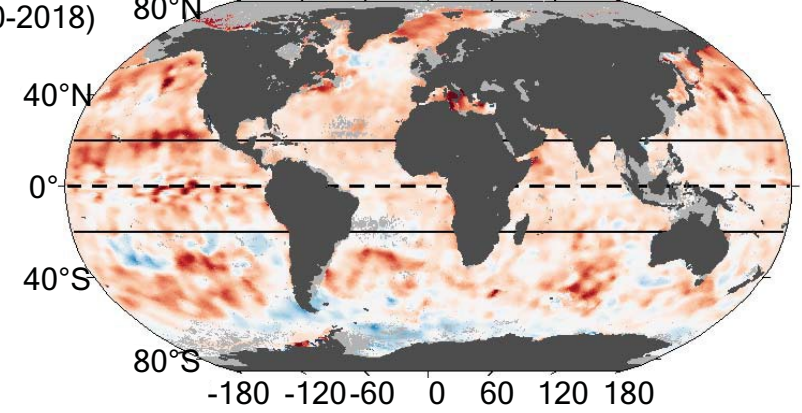

b

Sea surface temperature trend $\left({ }^{\circ} \mathrm{C} / \mathrm{dec}\right)$

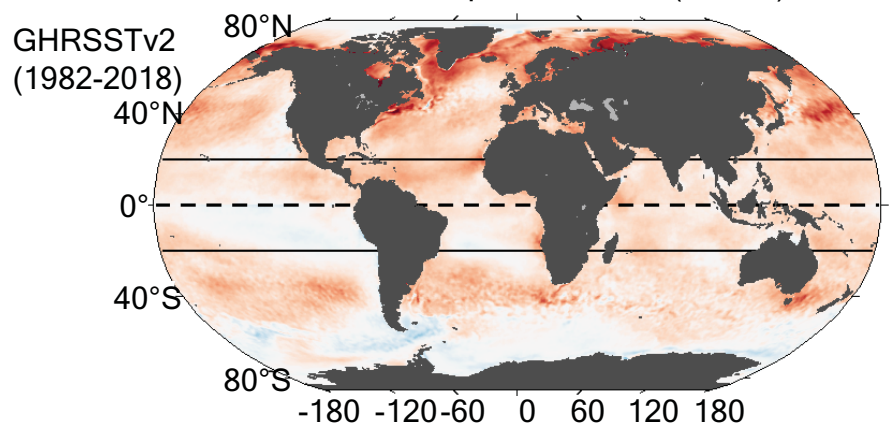

Extended Data Fig. 7 | Comparison between mixed-layer temperature trend and SST trends. a, Summer mixed-layer mean temperature trend from 1970 to 2018, as estimated in this study.b, Summer SST trend from 1982 to 2018, as estimated from the satellite-based product GHRSSTv2.c, Box plot showing the median (red) and interquartile range (blue box) of local summer SST trend
C

Global mean mixed-layer temperature trend $\left({ }^{\circ} \mathrm{C} / \mathrm{dec}\right)$

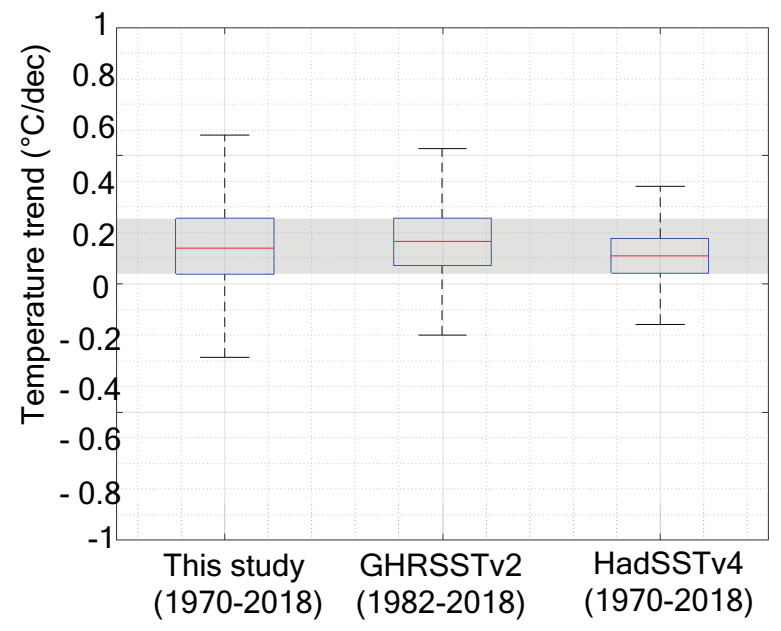

estimates from this study (mixed-layer mean temperature from 1970-2018), from the satellite-based product GHRSSTv2 (SST from 1982-2018) and from the in situ observation reconstruction product HadSSTv4 (SST from 1970-2018). The whiskers extend to the most extreme data points. 


\section{Article}

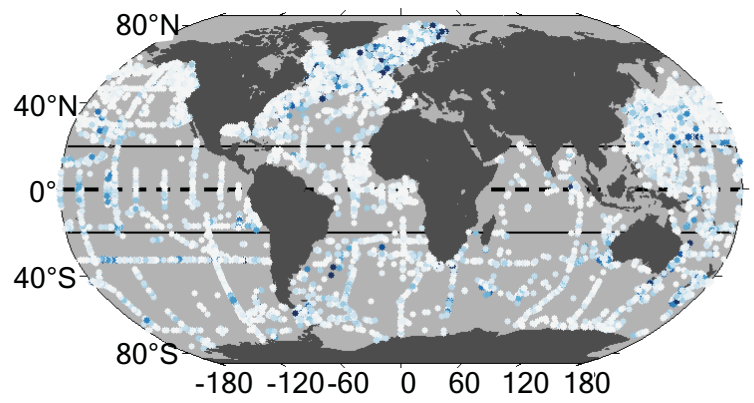

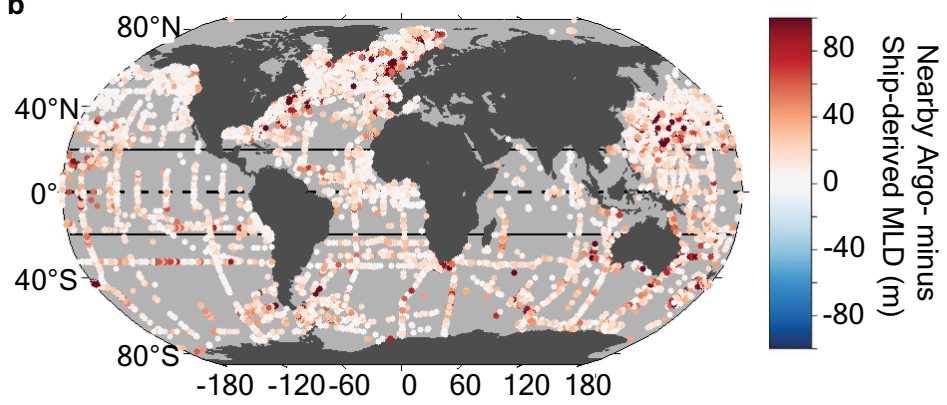

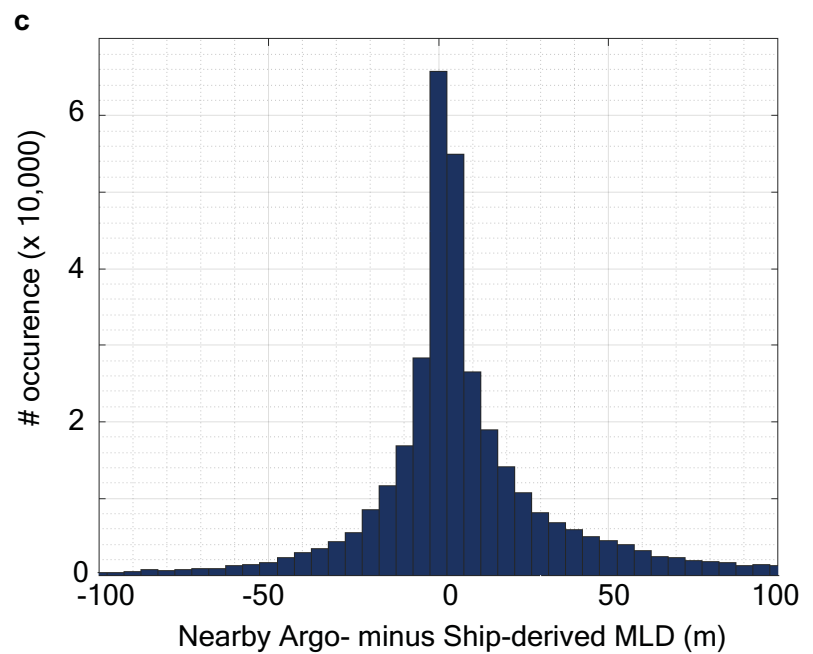

Extended Data Fig. 8 | Difference between Argo-and ship-based derived mixed-layer depth. a, b, Difference between mixed-layer depth (MLD) estimates coming from nearby (sampled within $330 \mathrm{~km}$ and 1.5 day) Argo and ship-based observation profiles (that is, co-located in time and space) for all instances for which we derived a smaller (a) or a greater (b) mixed-layer depth from the Argo profile than from the ship-based profile.c. Histogram of all differences. Because Argo started in the 2000s, the co-located profiles cover only the years $2000-2018$. 
a

Summer pycnocline stratification $\mathrm{N}^{2}$ trend $\left(\mathrm{s}^{-2} / \mathrm{dec}\right)$

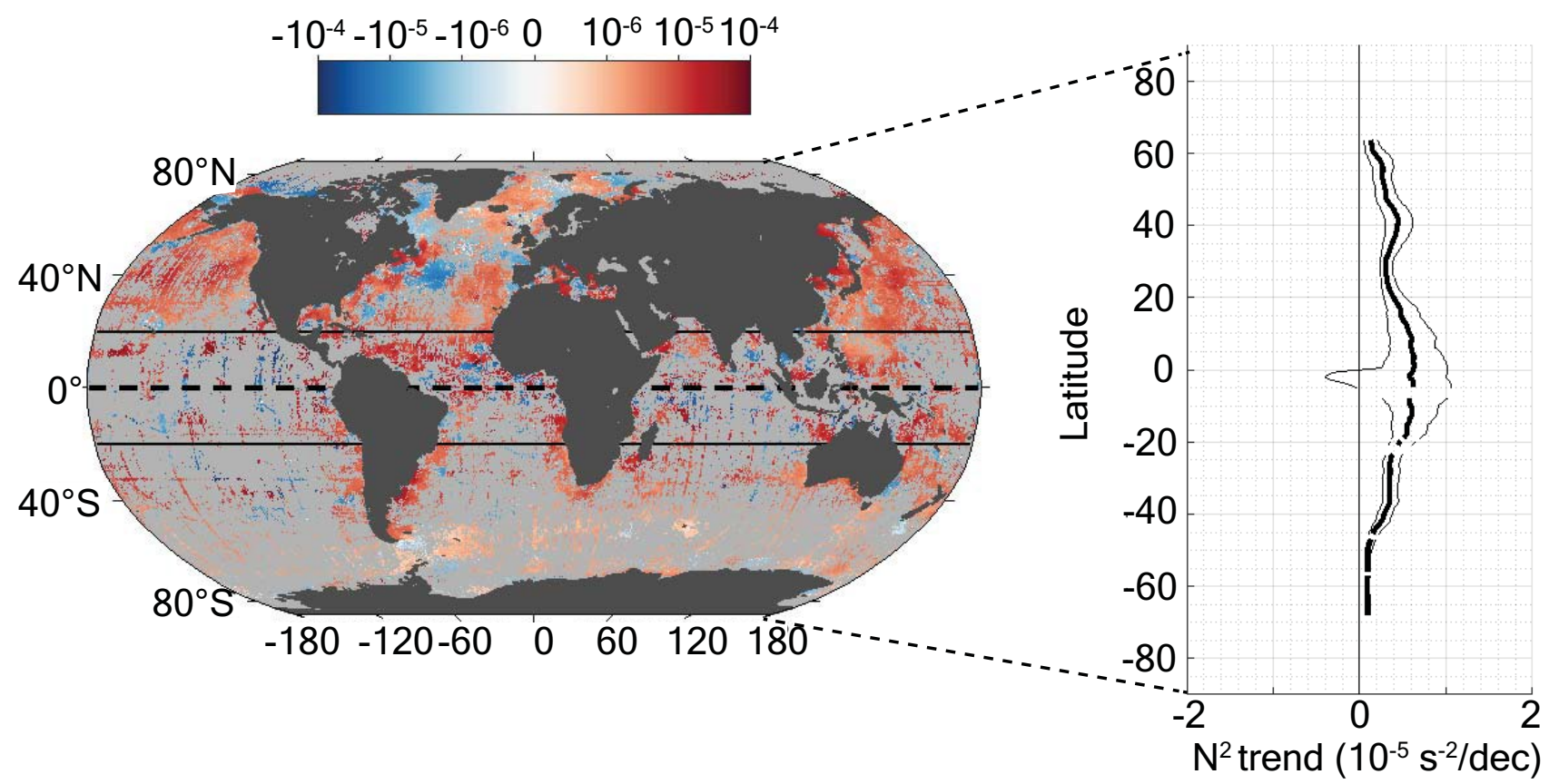

b

Summer mixed-layer depth trend $(\mathrm{m} / \mathrm{dec})$

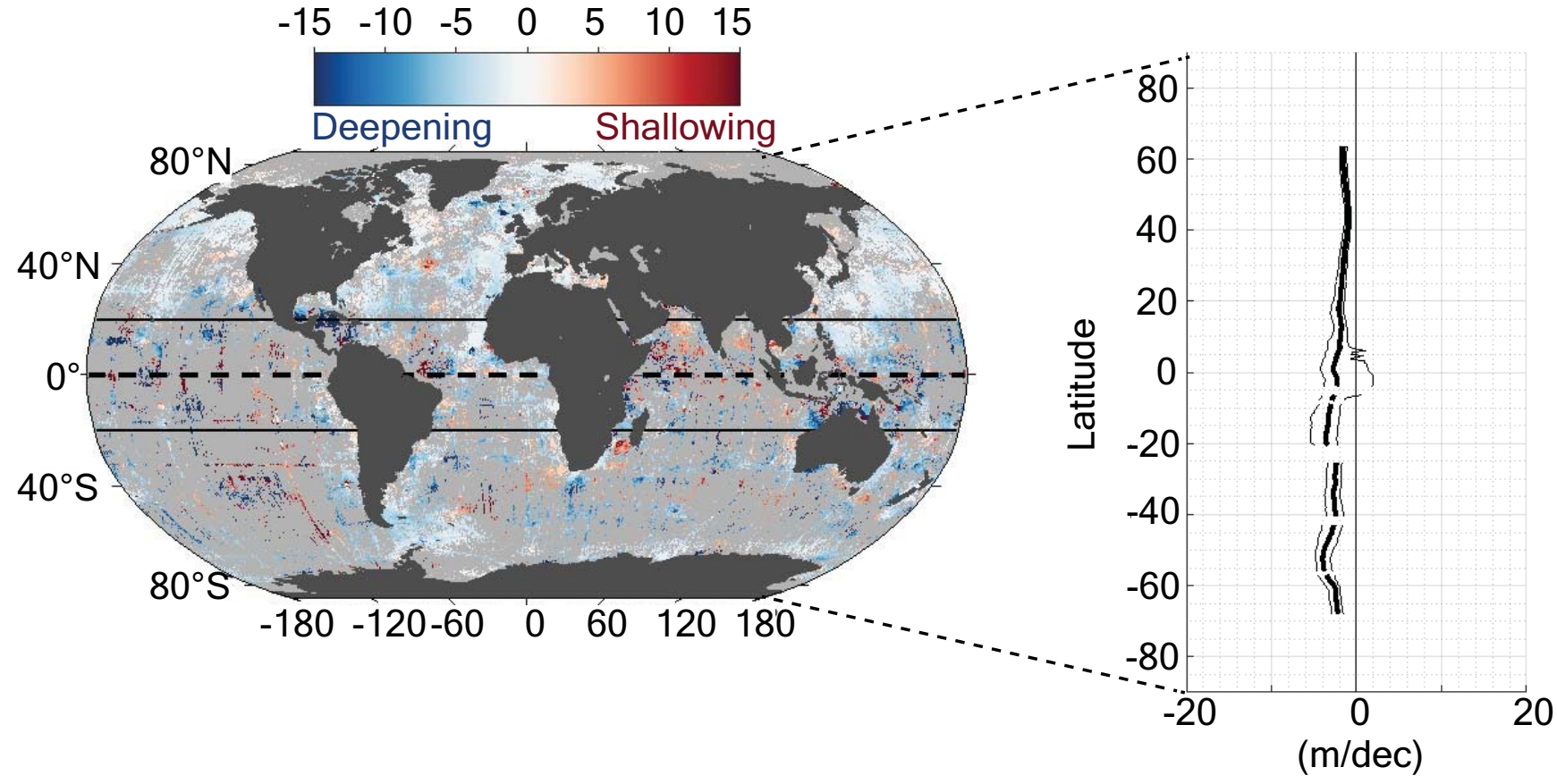

Extended Data Fig. 9|1970-2018 trends in summer pycnocline stratification and mixed-layer depth when using only ship-based profiles (removing all Argo and MEOP programme observations). a, Map of the 1970-2018 summer pycnocline stratification trend $\left(N^{2}\right.$ trend, in s-2 $\left.\mathrm{dec}^{-1}\right)$ along with the zonal-median value: median (thick black line) and 33th-66th percentile (thin black line). The red shading shows the global 33th-66th percentile range of the local trend estimates. Regions with no significant trend (see Methods) are shaded in grey on the map. b, As in a but for the summer mixed-layer trend, in $\mathrm{m} \mathrm{dec}^{-1}$ (mixed-layer deepening is shown as a negative trend). 